Check for updates

Cite this: Mater. Adv., 2021, 2, 4945

Received 12th May 2021

Accepted 27th June 2021

DOI: 10.1039/d1ma00429h

rsc.li/materials-advances

\section{The bright side of cellulosic hibiscus sabdariffa fibres: towards sustainable materials from the macro- to nano-scale}

\begin{abstract}
Ashvinder K. Rana*a and Vijay Kumar Thakur (D)*bc
Plant fibres are helically twisted cellulosic materials that are bonded together by lignin and hemicellulose matrices. Their physical, mechanical, and chemical properties depend enormously on the relative proportions of their chemical constituents, the atmospheric conditions, the age of the plant, and the collection time, among other factors. Hibiscus sabdariffa fibre is obtained by processing the stems or seeds of the Hibiscus sabdariffa plant (Hibiscus sabdariffa L.), which is an evergreen plant that is grown in almost all tropical regions of the world. Polymer composites or membranes developed utilizing plant fibres exhibit astonishing chemical resistance and mechanical and thermal properties, which are attributed to their chemical constituents, low density, and structural dimensions. However, further augmentation of the pre-existing properties of plant-fibre-fortified bio-composites can be achieved via enhancing the bonding between the hydrophilic plant fibres and the hydrophobic matrix, which should be possible by tailoring the surfaces of the plant fibres. In the present article, the methods and techniques employed for the extraction of Hibiscus sabdariffa fibre and its conversion into micro- and nano-forms are discussed. In addition, the effects of numerous surface tailoring strategies on the physicomechanical, thermal, water uptake, and humidity absorption characteristics of Hibiscus sabdariffa fibre have been surveyed to establish surface tailoring strategies and fibre dimension modification as feasible processes for producing useful Hibiscus sabdariffa fibres to address industrial needs. The surfacetailored plant macro-/micro-/nanofibres can fortify bio-composites and thus improve the utilization of Hibiscus sabdariffa fibre as a dependable and reasonable material for industrial purposes, which in turn may help to meet worldwide targets for creating and developing biomaterials for a better future.
\end{abstract}

\section{Introduction}

Plant fibres (PFs), as well as PF-fortified composite materials, are of enormous importance in both industry and fundamental research. ${ }^{1-3}$ PFs are ubiquitous all over the world, being present in most vegetables, shrubs, stalks, and seeds, as well as in any sort of woody crops or flora. As reported by the Food and Agricultural Organization (FAO), agriculturists produce approximately thirty-five million tons of PFs and animal fibres. A large quantity of this biomaterial is reshaped into other applicable items, while the leftover wastes create massive disposal issues. PFs are also known as cellulosic fibres because of their high cellulose contents relative to their other chemical

\footnotetext{
${ }^{a}$ Department of Chemistry, Sri Sai University, Palampur, 176061, India.

E-mail: ranaashvinder@gmail.com, ranaashvinder2020@gmail.com

${ }^{b}$ Biorefining and Advanced Materials Research Center, Scotland's Rural College

(SRUC), Kings Buildings, West Mains Road, Edinburgh, UK.

E-mail:Vijay.Thakur@sruc.ac.uk

${ }^{c}$ Department of Mechanical Engineering, School of Engineering,

Shiv Nadar University, Greater Noida, Uttar Pradesh, 201314, India
}

constituents, i.e., hemicelluloses and lignin. The benefits of utilizing bio-fibres ${ }^{4-6}$ include their low cost, plentiful availability, biocompatibility, biodegradability, low density, good mechanical properties, and reduced energy requirements during production, among others. (Fig. 1).

To date, several common PFs, such as banana, jute, sisal, coir, Saccharum ciliare, and Grewia optiva fibres, have been investigated, and their applicability in various fields has been explored..$^{7-11}$ However, due to their moisture-loving nature, poor resistivity against chemicals, and poor adhesion with hydrophobic matrices, their role has been limited. ${ }^{12-14}$ Thus, it is of great importance to modify PF surfaces by employing diverse physical and chemical methods to overcome their intrinsic downsides and successfully utilize these cellulosic materials in various applications ${ }^{15,16}$ (Fig. 1).

In the present article, we have thoroughly reviewed the methods and techniques employed for the extraction of Hibiscus sabdariffa fibres (HSFs) from the Hibiscus sabdariffa (HS) plant, the conversion of macroforms of HSFs to micro- and nano forms, and the functionalization of HSFs. Additionally, the utility 


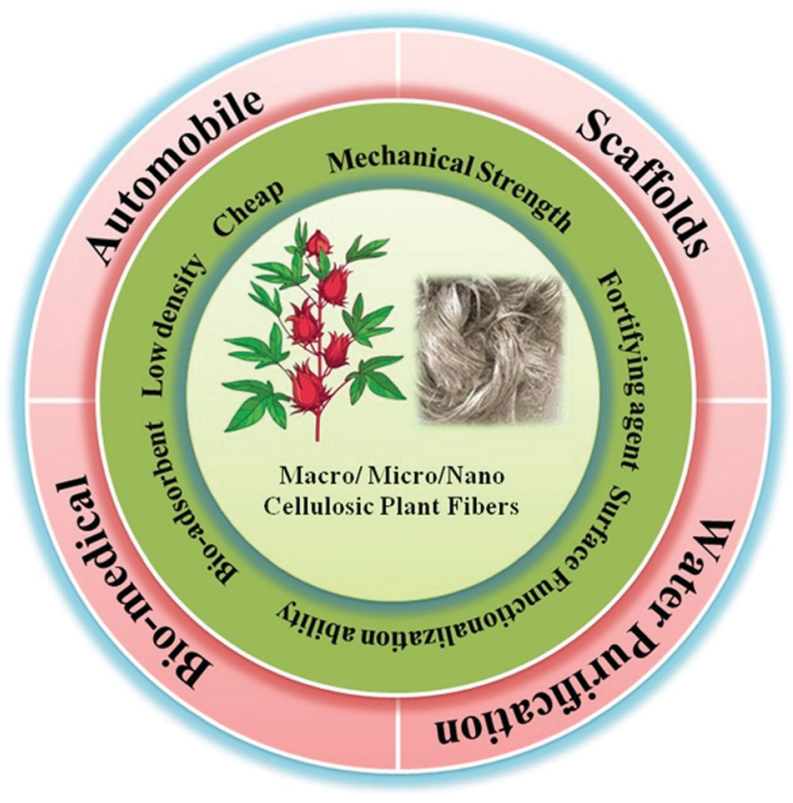

Fig. 1 Properties and applications of plant fibres in various fields.

of virgin and surface-modified HSFs as fortifying agents in polymer composites, as adsorbent materials for dyes and heavy metals in contaminated water, and as dielectric materials for different applications have also been examined ${ }^{17-19}$ (Fig. 2).

\section{Hibiscus sabdariffa plant and HSFs}

Hibiscus sabdariffa L. (HS), which is also known as roselle (Fig. 3a), is a perennial or annual crop, and is generally grown in developing nations since it can be produced with relative ease and may be utilized as a medicinal herb and for beverages, food and fibre. It is a woody-based subshrub and grows up to 2-2.5 $\mathrm{m}$ in height. Its leaves are deeply 3- to 5-lobed, have a length of $8-15 \mathrm{~cm}$ and occur alternately on the stems. ${ }^{20-22}$ The flowers of this plant display a white to light yellow colour and exhibit a dull red spot at the base of each petal. The flowers also feature a thick 1-2 cm calyx at the base, which grows and becomes plump and red upon the maturation of the fruits.

Parts of this plant have been consumed for different purposes throughout the world. In West Africa, its seeds and leaves are utilized in cooking, while in China the seeds are utilized for the extraction of oil and the plant extract is used for therapeutic purposes. In addition, this plant is also used to prepare hot and cold beverages in Africa and South Asia because of its antioxidant activity against chronic diseases, ${ }^{23,24}$ which has been associated with the presence of phenolic compounds (anthocyanins, flavonols, quercetin and kaempferol derivatives), phenolic acids (chlorogenic acid) and a specific organic acid (also known as hibiscus acid). ${ }^{25}$

In India, this plant is primarily grown for the extraction of natural fibre (Fig. 3b), which is further utilized in the fabrication of ropes, cords and cordage. ${ }^{26}$ The fibre may be substituted for jute in the manufacture of bags, cloth and wrappers. Hibiscus has also been utilized in Indian society as a diuretic and gentle laxative. In addition, the calyces of the plant are exported to Europe and the United States, where they are employed for the colouring of foods. ${ }^{27}$ In France, its green leaves are utilized as a fiery alternative to spinach for flavouring the rice dish thieboudienne and Senegalese fish. Several studies from different regions of the world regarding its cytotoxic and antimicrobial properties have been reported in the literature. ${ }^{28-32}$

\section{Extraction of HSFs}

HSFs can be extracted from the bast of the plant as well as from its seeds. The various attempts made by researchers to extract HSFs have been discussed below.

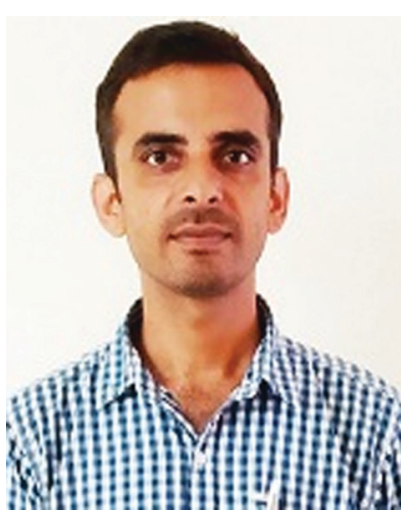

Ashvinder K. Rana
Dr Ashvinder Kumar is a specialist in macro/nanocomposites. $\mathrm{He}$ obtained his PhD (2014) from NIT Hamirpur India, MSc (2008) from NIT Jalandhar India, and BSc (Chemistry) (2003) from CSKHPKV Palampur. He has been working at the Sri Sai University, Palampur as an Assistant Professor since August 2013. His priority research areas are materials science, polymer composites, and biomaterials. He has guided three MPhil students and is presently guiding another MPhil student in their dissertation work. He has published more than 32 international publications (research articles and book chapters).

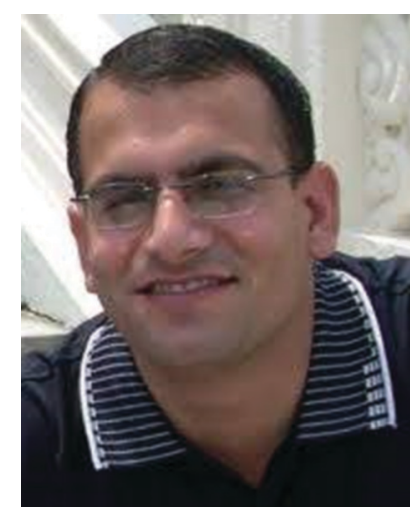

Vijay Kumar Thakur
Vijay Kumar Thakur is currently a Professor in the Biorefining and Advanced Materials Research Centre at SRUC, Edinburgh, UK, and holds an Adjunct Professor position at several other universities. He has previously held faculty positions at Cranfield University, UK, Washington State University, USA, and Nanyang Technological University, Singapore. His research activities span the disciplines of biorefining, chemistry, chemical engineering, manufacturing, materials science, and nanotechnology, as well as all aspects of sustainable and advanced materials. He has published over 250 SCI journal articles, 2 patents, 50 books, and 40 book chapters in areas concerning polymers, nanotechnology, and materials science. 

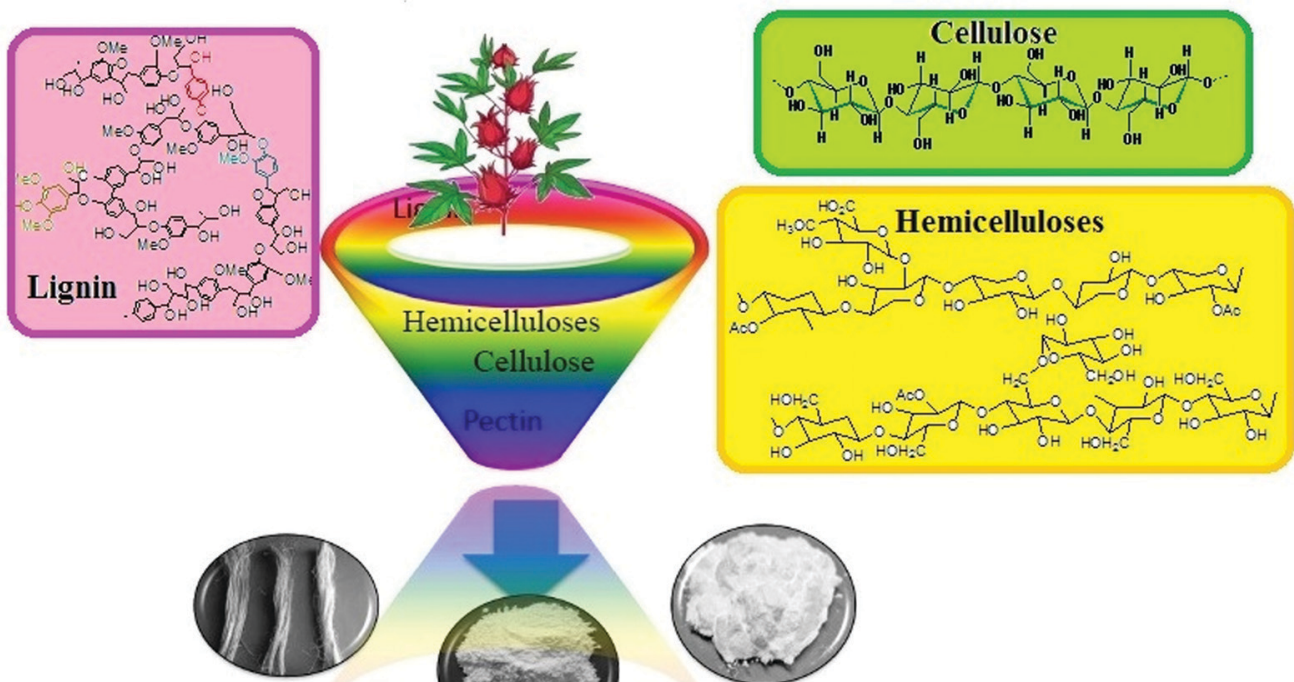

Cellulose fiber

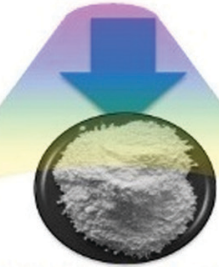

Micro crystalline

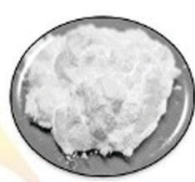

Nano crystalline

cellulose cellulose

\section{Different forms of HSFs have been utilised for development of} Polymer Composites and may be used for removal of heavy metals and dyes from contaminated water
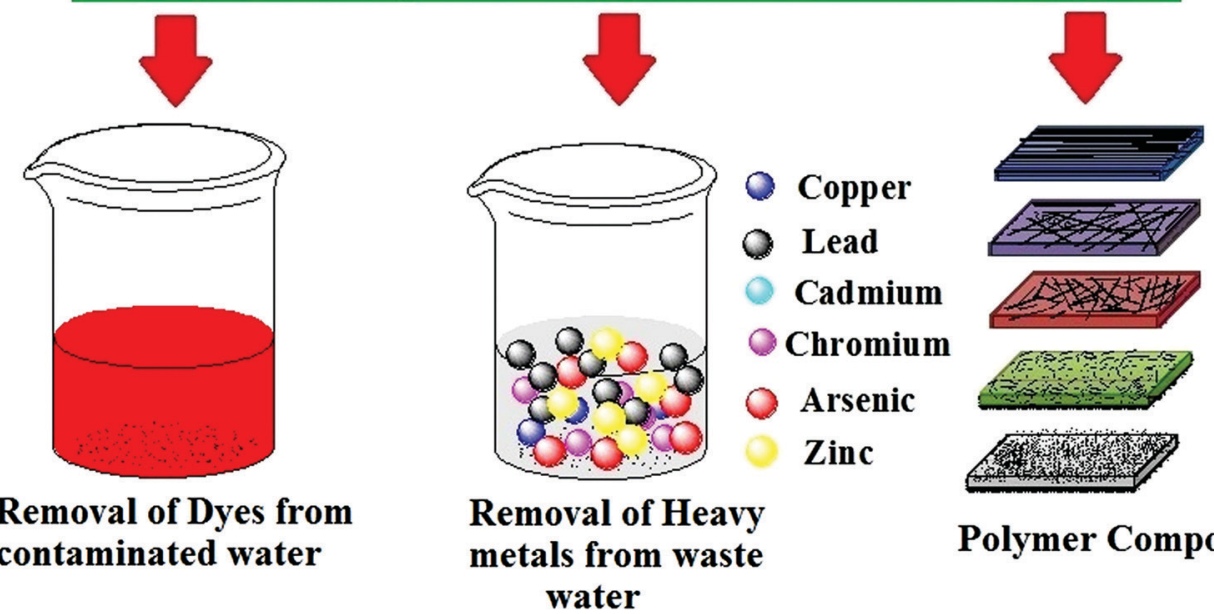

Polymer Composites

Fig. 2 Different forms of fibres that have been extracted from HSFs and their applicability in water purification and polymer composites.
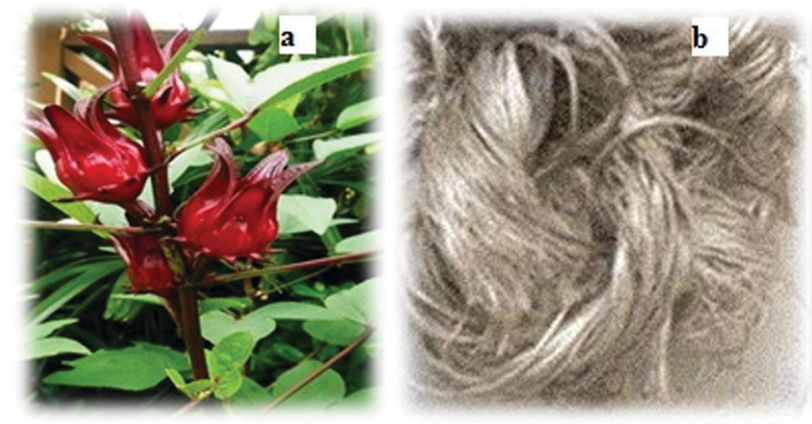

Fig. 3 (a) The HS plant and (b) HSFs.

\section{Extraction from plant bast}

Anaerobic and/or aerobic bacterial retting procedures

Cellulosic fibres from the HS plant were separated by Azeez and Onukwuli $^{33}$ in laboratory conditions using the procedure reported by Phog et al. ${ }^{34}$ They initially removed the bast from the stem and then cut it into 4-6 ft lengths. The plant bast was then immersed in deionized water for eighteen days with occasional washing at an interval of every three days. The fibres were subsequently extracted after 18 days and dried at $60{ }^{\circ} \mathrm{C}$. Agarwal and Ela Dedhia ${ }^{35}$ utilized two types of techniques, i.e., an anaerobic microbial and an aerobic retting technique, for the successful extraction of fibres from HSF stems (Fig. 4). The anaerobic microbial retting method involved immersing stems in a mud tank, which is filled with $80 \mathrm{~L}$ of water, $20 \mathrm{~L}$ of 


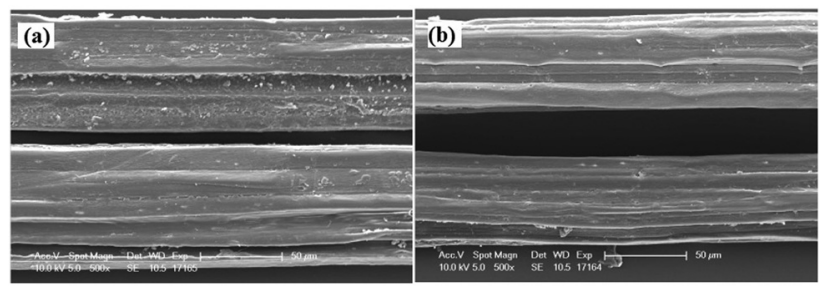

Fig. 4 Scanning electron microscope (SEM) images of (a) aerobically and (b) anaerobically retted HSFs. ${ }^{35}$ Figure reproduced from ref. 35 under Creative Commons Attribution 4.0 International (CC-BY) License 4.

microbial consortium and $500 \mathrm{~g}$ of vegetable and fruit waste and enclosed within polyethene bags to prevent the passage of air, for a specific time period. The fibres were then extracted by washing with water and air-dried. The aerobic method of fibre extraction was very similar to the bacterial method reported by Akubueze and co-workers, ${ }^{36}$ which is generally employed by local peoples of the Himalayan region. This bacterial retting process is a natural water retting process, which includes immersing the stalks in ponds or rivers for three weeks during the summer season or under artificially manipulated conditions so that the temperature of the water is approximately $30{ }^{\circ} \mathrm{C}$. During this period, fungi and bacteria that grow naturally in the water cause the decomposition of the non-fibrous binding material and thus lead to the extraction of the pure fibres.

\section{Chemical retting procedure}

In addition to the bacterial retting approach, Akubueze and coworkers $^{36}$ also reported a sodium-bisulphate-based chemical technique for the extraction of pure fibres. In the chemical retting approach, stalks were immersed in a solution of 5-7\% $\mathrm{NaOH}(\mathrm{w} / \mathrm{v})$ and $1 \% \mathrm{NaHSO}_{4}(\mathrm{w} / \mathrm{v})$, keeping a fibre to liquid ratio of $1: 20$, and then boiled for $90 \mathrm{~min}$. The boiled mixture was neutralized with $0.3 \%$ acetic acid and subsequently washed with water to obtain a neutral $\mathrm{pH}$. The fibres were then extracted, oven-dried, and combed properly. This process is faster than bacterial processes, but has been reported to influence the physicochemical properties of the fibres in a negative way. Okeke and co-workers ${ }^{37}$ carried out the retting of fibres employing a hydrogen-peroxide-based chemical technique. They initially washed the stems with water to remove the sand and dirt present on their surface. In the next step, the bast was extracted from stalks and cut into small pieces $(10 \mathrm{~cm})$ for better processing under laboratory conditions. These small pieces were then boiled in distilled water for $3 \mathrm{~h}$ and subsequently scoured in $2 \%$ hydrogen peroxide solution with continuous boiling for $45 \mathrm{~min}$. Afterwards, the fibres were rinsed with tap water, airdried, and then dried at $70{ }^{\circ} \mathrm{C}$ to obtain a constant weight.

\section{Pure cellulose extraction}

\section{Isolation from HS plants}

Goswami et al. ${ }^{38}$ extracted cellulose from HSFs as per the technique reported by Nazir et al. ${ }^{39}$ with a slight modification. In the first step, the HSFs were dewaxed in a hexane-ethanol solvent system $(2: 8 \mathrm{v} / \mathrm{v})$, and subsequently macerated in $2 \%$ alkali solution for a given time, delignified with a mixture $(1: 1 \mathrm{v} / \mathrm{v})$ of acetic acid (30\%) and hydrogen peroxide $(10 \%)$ for $180 \mathrm{~min}$ at $80{ }^{\circ} \mathrm{C}$, and finally bleached with $10 \%$ hydrogen peroxide for $3 \mathrm{~h}$ at $60{ }^{\circ} \mathrm{C}$ to obtain lignin- and hemicellulosefree pure cellulosic fibres. While many methods for the extraction of cellulose from HSFs are available in the literature, ${ }^{40}$ the method used by Goswami et al. ${ }^{38}$ is chlorine-free and gives a higher percent yield. Cazaurang et al. ${ }^{41}$ extracted cellulose from henequen fibre utilizing a series of steps. Their procedure involved the hydrolysis of PFs with $\mathrm{H}_{2} \mathrm{SO}_{4}(0.4 \mathrm{wt} \%)$, followed by chlorination with sodium hypochlorite, $\mathrm{NaOH}$ treatment (20 wt\%) and finally bleaching with $5 \mathrm{wt} \% \mathrm{NaOCl}$ solution. Chattopadhyay and Sarkar ${ }^{42}$ initially extracted holocellulose from PFs by treating them with a sodium chlorite $(0.7 \% \mathrm{w} / \mathrm{v})$ and sodium bisulphate solution $(5 \% \mathrm{v} / \mathrm{v})$, which was finally reacted with an alkali solution (17.5 wt\%) for the possible removal of hemicelluloses and subsequent isolation of pure cellulose. A chlorine-free approach was also adopted by Sun et al. $^{43}$ They pre-treated PFs with an alkali/ethanol mixture $(50: 50 \mathrm{v} / \mathrm{v})$ and subsequently with hydrogen peroxide $(0.5-3.0 \%)$, $10 \%(\mathrm{w} / \mathrm{v}) \mathrm{NaOH}-\mathrm{Na}_{2} \mathrm{~B}_{4} \mathrm{O}_{7} \cdot 10 \mathrm{H}_{2} \mathrm{O}$ solution and a nitric acid $(70 \%)+$ acetic acid $(80 \%)$ solution for the extraction of pure cellulose.

\section{Isolation from HS seeds}

In addition to the extraction of pure cellulose from HSFs, attempts have also been made to extract cellulose from HS seeds. Adewuyi and Pereira ${ }^{44}$ isolated cellulose from seeds as per the method reported by Flauzino Neto et al. ${ }^{45}$ For extraction, a mixture of $200 \mathrm{~g}$ of hexane-extracted seeds (defatted seeds) with alkali solution $(2 \% \mathrm{NaOH})$ was prepared in a beaker, and was subsequently stirred continuously for $5 \mathrm{~h}$ at $80{ }^{\circ} \mathrm{C}$, filtered, washed with distilled water and oven-dried to a constant weight. The treatment with alkali solution was then repeated twice to obtain a brown product. In the next step, the brown product was repeatedly treated with a mixture $(1: 1 \mathrm{v} / \mathrm{v})$ of acetate buffer and aqueous sodium chlorite until the fibres became completely white.

\section{Chemical composition of HSFs}

Agarwal and Dedhia compared the impact of two different fibre extraction methods, water retting and microbial retting, on the percent yield of fibre as well as the chemical composition of the extracted fibres. ${ }^{35}$ Both dried and freshly harvested stalks were used for this purpose; use of the latter was found to have a better percent yield. Additionally, between the microbial and water retting processes, the former was reported to give a better percent yield $(7.10 \%)$ than the latter $(6.54 \%)$. The impact of different the retting processes on the chemical composition of HSFs is presented in Table 1.

Upon comparison, we found that the microbial retting process is the better strategy for fibre extraction as it gives higher cellulosic content percentages in the extracted fibres. A comparison of the chemical composition of HSFs as reported 
Table 1 The influence of different retting processes on the chemical compositions of HSFs

Type of retting process \% Cellulose \% Hemicellulose \% Lignin content Ref.

\begin{tabular}{llllll}
\hline Water retting & 60.78 & 26.7 & 9.10 & 2.12 & 35 \\
Microbial retting & 63.52 & 23.8 & 7.6 & 1.23 & 35
\end{tabular}

by Razali et $a l^{46}$ and some other common PFs has been presented in Table 2. Razali and co-workers utilized different aged plants (3, 6 and 9 months) to study the impact of water retting on the chemical composition of the retted fibres. By comparing the chemical composition of HSFs with other PFs, it can be found that HSF fibres are a strong contender among PFs as the HSF fibres have higher cellulosic contents and thus may revolutionize the polymer composite and water treatment industries.

\section{Comparison of the physicochemical properties of HSFs and some PFs}

\section{Physical and tensile properties}

The physical properties of fibres may vary depending on the region, type of extraction methods employed, and climatic conditions, among other factors. One researcher from Nigeria evaluated various physical and mechanical parameters of HSFs as per the standard methods and reported these fibres to have a diameter of $0.021 \mathrm{~mm}$, density of $0.514 \mathrm{~g} \mathrm{~cm}^{-3}$, aspect ratio of
4761.9 , water absorption efficiency of $366.67 \%$, tensile strength of $43.5336 \mathrm{MPa}$, and tensile modulus of $2294.6 \mathrm{MPa} .^{33}$ Furthermore, enhancement of the tensile strength and modulus of the fibres and reduction of their physical parameters, such as fibre diameter, density, aspect ratio and percent water adsorption have been reported after surface modification of fibres with alkali and sodium lauryl sulphate. The maximum increase in tensile strength (166.43 MPa) and tensile modulus (3472.6 MPa) was reported in the case of alkali-treated HSFs. However, contrary to the trend in the mechanical properties, other physical parameters were found to be reduced after chemical treatments, and the minimum values were reported for sodiumlauryl-treated fibres. The fibre diameter, density, aspect ratio and percent water adsorption values for the alkali- and SLS-treated fibres were reported to be $0.017 \mathrm{~mm}, 0.366 \mathrm{~g} \mathrm{~cm}^{-3}, 5882.35$ and 333.33; and $0.018 \mathrm{~mm}, 0.2 \mathrm{~g} \mathrm{~cm}^{-3}, 5556$ and 312.5, respectively. This behaviour was attributed to the removal of hemicelluloses from the fibre surface after mercerization and further enhancement of their hydrophobic character after surface functionalization with SLS. Similar to this work, Okeke and co-workers ${ }^{37}$ also reported a reduction in fibre diameter, aspect ratio, density and moisture absorption after the mercerization of the fibres. Oladimeji and Okechukwu $^{81}$ investigated the effect of three different chemical treatments, namely, alkali, sodium lauryl sulphate and ethylene diamine tetraacetic acid, on the tensile and water adsorption behaviour of HSFs. HSFs with a gauge length of $100 \mathrm{~mm}$ were used for mechanical testing. The highest tensile toughness was reported for ethylene-diamine-treated fibres (173.75 MPa), followed by $\mathrm{NaOH}$-treated $(169.24 \mathrm{MPa})$, sodium-lauryl-sulphate-treated

Table 2 Chemical compositions of HSFs and other common PFs

\begin{tabular}{|c|c|c|c|c|c|c|c|c|}
\hline Plant fibre source & Density $\left(\mathrm{g} \mathrm{cm}^{-3}\right)$ & $\begin{array}{l}\% \\
\text { Cellulose }\end{array}$ & $\begin{array}{l}\% \\
\text { Hemicelluloses }\end{array}$ & \% Lignin & $\%$ Pectin & $\%$ Ash Content & $\%$ Wax & Ref. \\
\hline Abaca & 1.50 & $55-63$ & $20-25$ & $7-9$ & - & 3 & 0.2 & 47 and 48 \\
\hline Flax & 1.50 & $62-71$ & $16-18$ & $1.8-2.0$ & $2.0-2.5$ & - & 1.5 & 49 \\
\hline Hemp & $1.48-1.49$ & $70.2-74.4$ & $17.9-22.4$ & 0.8 & 0.9 & 0.8 & 0.7 & $49-51$ \\
\hline Henequen & 1.40 & 60.6 & 28 & 8 & - & 1.2 & - & 48 \\
\hline Kenaf & 1.20 & $44-57$ & $8-13$ & 21.5 & 0.6 & 2.5 & - & 49 and 52 \\
\hline Banana & 1.35 & $60-65$ & $6-8$ & $5-10$ & - & 1.2 & - & 53 \\
\hline Cotton fibres & $1.52-1.56$ & $82-90$ & $3-5$ & - & 0.0 & & 0.6 & 47,50 and 53 \\
\hline Pineapple & 1.44 & 68 & $15-20$ & $2-4$ & $8-12$ & & $4-7$ & 53 \\
\hline Ramie & $1.51-1.55$ & $68-91$ & $5-16$ & $0.6-0.7$ & 1.9 & - & 0.3 & 48,50 and 54 \\
\hline Sisal & 1.45 & $67-78$ & $10-14$ & $8-11$ & - & - & - & 55 \\
\hline Coir Fibre & 1.20 & $36-43$ & 0.2 & $41-45$ & $3-4$ & - & - & 56 and 57 \\
\hline Kapok & 0.37 & 50.7 & 49.3 & - & 13.4 & - & - & 58 \\
\hline Sea Grass & 1.5 & 57 & 38 & 5 & - & 10 & - & 59 \\
\hline Althaea & 1.18 & 44.6 & 13.5 & 2.7 & - & 2.3 & - & 60 \\
\hline Prosopis juliflora fibre & 0.58 & 61.65 & 16.64 & 17.11 & - & 5.2 & 0.61 & 61 \\
\hline Acacia leucophloea & 1.38 & 68.09 & 13.60 & 17.73 & - & 2.3 & - & 62 \\
\hline Ferula communis & 1.24 & 53.3 & 8.5 & 2.7 & - & 2.3 & - & 63 \\
\hline Tamarind & 1.042 & 59 & 22 & 19 & - & - & - & 64 and 65 \\
\hline Cyperus pangorei & 1.102 & 68.5 & - & 17.88 & - & 3.56 & 0.17 & 66 \\
\hline Ipomoea staphylinaplant & 1.401 & 72.26 & 13.6 & 19.56 & - & 1.40 & 1.51 & 67 \\
\hline Sansevieria ehrenbergii & 0.887 & 80 & 11.25 & 7.8 & - & 0.6 & 0.45 & 68 \\
\hline Phormium tenax & - & $45.1-72$ & $8-13$ & $11.8-13$ & 0.6 & $2-5$ & 0.8 & 49 \\
\hline Sansevieria cylindrica & 0.92 & 79.7 & 10.13 & 3.8 & - & - & 0.09 & 69 \\
\hline $\begin{array}{l}\text { Pennisetum orientale } \\
\text { grass }\end{array}$ & 1.04 & 60.3 & 16 & 12.45 & - & - & 1.9 & 70 \\
\hline Piassava & 0.9 & 28.6 & 25.8 & 45 & - & - & - & 48 \\
\hline$H S F s$ & $1.33-1.42$ (as per ASTM D792) & $\begin{array}{l}58.63- \\
64.50\end{array}$ & $16.27-20.82$ & $\begin{array}{l}6.21- \\
10.26\end{array}$ & - & $1.5-2.08$ & - & 46 \\
\hline
\end{tabular}


(87.44 MPa) and raw HSFs (43.13 MPa). Improved water adsorption was also reported after surface functionalization of the HSFs. A comparison of the mechanical strength of HSFs and other PFs is presented in Table 3. Upon contrasting the mechanical properties, it can be reasoned that HSFs could supplant other PFs in the polymer composite industry.

\section{Thermal behaviour}

The thermal stability of PFs relies chiefly on the relative proportion of the prime constituents of the fibres such as hemicelluloses, cellulose and lignin, which subsequently depends on the technique utilized for the separation of the fibres, the season, the growth region, and the climatic conditions, among other factors. Among the various constituents, cellulose is the most stable and has been reported to decompose in the range of $250-400{ }^{\circ} \mathrm{C}$, which releases char and non-ignitable and combustible gases. ${ }^{82,83}$ Hemicelluloses are somewhat less stable than cellulose and undergo decay into more nonflammable gases at $200-270{ }^{\circ} \mathrm{C}$. The last component is lignin, which decomposes over a relatively wide range of $170-400{ }^{\circ} \mathrm{C}$ and produces significant char residue. We have compiled the reported thermal stability parameters of various fibres; however, it should be kept in mind that the thermal stability of fibres will fluctuate depending on the type of instruments utilized, heating rate, mass of fibre used for testing and the environmental conditions utilized for assessing thermal quality. The initial decomposition temperature (IDT) and final disintegration temperature (FDT) of HSFs and various crude PFs are presented below (Table 4).

\section{Crystallinity index}

The crystallinity index of PFs depends upon the relative proportions of the three constituents of the fibres, i.e., hemicelluloses, lignin, and celluloses. In general, the greater the amount of cellulose, the higher the crystallinity will be. The percent crystallinity of HSFs and some other common PFs have been listed in Table 5; these values were assigned using the Segal method for evaluating X-ray powder diffraction (XRD) spectra. For calculation of percent crystallinity, the intensity of the 002 crystalline peaks and the height of the minimum peak between the crystalline (002) and amorphous peak (101) are generally used.

\section{Synthesis of micro- and nanoforms of HSF}

Nanocelluloses have higher potential than the micro-fibrillated and macroscopic forms of cellulose in various industrial applications, particularly as fortifying agents in the fabrication of nanocomposites. The force behind the conversion of macroscopic fibres to the micro- and then nanoscale is the high surface area, which generally leads to low filler volume fractions and improved properties, such as mechanical, thermal, and dielectric properties, of the resulting composites. Researchers have utilized mechanical methods either alone or in combination with chemical methods for the synthesis of nano- and microforms of HSF fibres. The different types of fibres that can be prepared or synthesized from the bast of the HS plant are summarized in Fig. 5. Among these, the macrofibres are prepared using a

Table 3 A comparison of the mechanical properties of HSFs vs those of common PFs

\begin{tabular}{|c|c|c|c|c|}
\hline Fibre name & Gauge length (mm) & Tensile strength (MPa) & $\%$ Elongation & Ref. \\
\hline Abaca leaf fibre & 10 & $418-486$ & - & 71 \\
\hline Abaca fibre & 100 & 400 & $3-10$ & 48 \\
\hline Bamboo & 100 & 503 & 1.40 & 48 and 56 \\
\hline Banana & 150 & 600 & 3.36 & 47 and 56 \\
\hline Henequen & - & $430-570$ & $3.7-5.9$ & 48 \\
\hline Okra & 50 & $184-557.3$ & $4-8$ & 72 \\
\hline Sisal & 50 & $530-640$ & $3-7$ & 48 and 73 \\
\hline Kapok & - & $45-64$ & $2-4$ & 74 \\
\hline Kenaf & 10 & $427-519$ & & 71 \\
\hline Hemp & - & $550-900$ & $2-4$ & 50 and 51 \\
\hline Jute & 60 & $393-773$ & $1.5-1.8$ & 50 \\
\hline Flax & - & $345-1500$ & $0.2-3.2$ & 72 \\
\hline Ramie & - & $220-938$ & $2-3.8$ & 73 \\
\hline Cotton & - & 400 & $7.0-8.0$ & 50 \\
\hline Oil Palm & - & 248 & 25 & 48 \\
\hline Sea Grass & - & $453-692$ & $13-26.6$ & 74 \\
\hline Pennisetum orientale & 10 & 17-19 & - & 70 \\
\hline Lygeum spartum L. & 40 & $64.63-280.03$ & $1.49-3.74$ & 75 \\
\hline Raphia farinifera & 45 & $152-270$ & $2.5-4.4$ & 76 \\
\hline Piassava & 50 & $131.1 \pm 27.1$ & $11.9 \pm 4.3$ & 77 \\
\hline Acacia leucophloea & 50 & $317-1608$ & $1.38-4.24$ & 62 \\
\hline Tamarind & 50 & 61.2 & 6.22 & 78 \\
\hline Cyperus pangorei & 50 & 196 & 1.69 & 66 \\
\hline Prosopis juliflora fibre & 20 & 558 & - & 61 \\
\hline Pennisetum purpureum & 100 & 73 & 1.40 & 79 \\
\hline Isora fibre & 70 & 561 & 5 & 80 \\
\hline \multirow[t]{2}{*}{ HSFs } & 100 (Diameter: $0.021 \mathrm{~mm}$; aspect ratio: 4761.63 ) & $43.53 \pm 1.4$ & 10.28 & 33 \\
\hline & 20 (Diameter: $40-150 \mu \mathrm{m})$ & $228.57-414.72$ & - & 46 \\
\hline Pinus roxburghii & 324 & 11.15 & 10.68 & 50 \\
\hline
\end{tabular}


Table 4 A comparison of the thermal stability of HSFs and different PFs

\begin{tabular}{lll}
\hline Fibre type & IDT \& FDT $\left({ }^{\circ} \mathrm{C}\right)$ & Ref. \\
\hline Bamboo fibre & $208 \& 331$ & 84 \\
Coir fibres & $242 \& 340$ & 85 \\
Flax fibres & $279.9 \& 489.1$ & 86 \\
Banana fibres & $238 \& 399$ & 87 \\
Cannabis indica (indian hemp fibres) & $287 \& 490$ & 88 \\
Kenaf fibre & $270 \& 402$ & 89 \\
Hemp fibre & $250 \& 360$ & 90 \\
Okra fibre & $228 \& 466$ & 91 \\
Kapok fibre & $252 \& 380$ & 92 \\
Pita (Agave americana) fibre & $240 \& 432$ & 93 \\
Ramie fibre & $300 \& 430$ & 94 \\
Pineapple leaf fibres (PALFs) & $220 \& 370$ & 95 \\
Roselle (Hibiscus sabdariffa) fibre & $225.7 \& 463$ & 83 \\
Sisal fibre & $250 \& 363$ & 96 \\
Pennisetum purpureum & $258 \& 400$ & 79 \\
Ferula communis & $250 \& 360$ & 63 \\
Ipomoea staphylinaplant & $235 \& 380$ & 67 \\
Lygeum spartum L & $245 \& 360$ & 75 \\
Attalea funifera & $258 \& 375$ & 77 \\
Acacia leucophloea & $250 \& 390$ & 62 \\
Thespesia populnea & $245 \& 370$ & 97 \\
Cyperus pangorei & $245 \& 440$ & 66 \\
Cissus quadrangularis fibre & $240 \& 342$ & 98 \\
Thespesia lampas fibre & $270 \& 415$ & 99 \\
& &
\end{tabular}

Table 5 Percent crystallinity data for HSFs and different PFs

\begin{tabular}{lll}
\hline Fibre type & Percent crystallinity & Ref. \\
\hline Pineapple leaf fibre & $44-60$ & 100 \\
Banana fibre & 64.40 & 101 \\
Hemp fibre & 83.70 & 102 \\
Jute & 71.00 & 103 \\
Agave americana fibre & 67.92 & 104 \\
Kenaf & 48.20 & 105 \\
HSFs & 77.20 & 106 \\
Indian hemp fibre & 67.07 & 107 \\
Okra fibre & 50.60 & 108 \\
Coir fibre & 35.02 & 109 \\
Sisal fibre & 71.70 & 110 \\
Flax fibre & 72.20 & 111 \\
Bamboo fibre & 30.54 & 112 \\
Kapok & 35.74 & 113 \\
Cotton & 58.12 & 113 \\
Sansevieria ehrenbergi & 52.27 & 68 \\
Hetropogan contortus & 54.1 & 114 \\
Prosopis juliflora & 46 & 61 \\
Raphia farinifera fibre & 66.6 & 76 \\
Thespesia populnea fibre & 48.17 & 97 \\
Ferula communis & 48 & 63 \\
Ipomoea staphylinaplant & 43.96 & 67 \\
Isora fibre & 70.9 & 80 \\
Lygeum spartum L. & 46.19 & 75 \\
Pennisetum orientale & 33.5 & 70 \\
HSFs & 77.20 & 115 \\
& &
\end{tabular}

chopper or grinder, and the micro- and nanoforms require more tedious procedures.

\section{Extraction of cellulose microfibres from HS plants}

The size of microfibres lies between those of nanocellulose and macroscale cellulose fibres, with a diameter range of 100-1000 nm.

Several researchers have utilized the steam explosion technique for the conversion of HSFs into microforms. ${ }^{116-118}$
Karakoti et al. ${ }^{116}$ completed the conversion process in four steps. In the first step, the chopped HSFs $(10 \mathrm{~cm})$ were treated with $2 \%$ alkali solution in an autoclave for one hour; the temperature and pressure were maintained at $120{ }^{\circ} \mathrm{C}$ and $20 \mathrm{lb}$, respectively. In the next step, the fibres were washed, oven-dried to a constant weight and then bleached with $\mathrm{NaClO}_{2}$. The bleached fibres were then hydrolysed with an oxalic acid solution in an autoclave after attaining a pressure of $20 \mathrm{lb}$. In the final step, the isolated microfibrils were mechanically stirred for $4 \mathrm{~h}$ at $8000 \mathrm{rpm}$. The synthesized microfibres were characterized using XRD, thermogravimetric analysis (TGA) and scanning electron microscopy (SEM), and were reported to have better morphological, thermal, chemical, and hydrophobic properties than raw HSFs. Additionally, increased crystalline properties and reduced fibre diameter (as low as $5 \mu \mathrm{m}$ ) have also been reported after the conversion of HS fibres into microforms. Sonia and Dasan ${ }^{117,118}$ utilized almost the same procedure as reported by Karakoti $e t$ al. for the conversion of HSFs into microforms. However, they made a slight change to the bleaching process in the second step, incorporating six repeated treatments with a mixture of acetic acid and sodium hydroxide solution $(3: 1 \mathrm{v} / \mathrm{v})$ and a sodium hypochlorite solution for one hour each. Similar to the results of Karakoti et al., they also reported increased thermal properties and a drastic reduction in the length and diameter of the treated fibres. Aseer and Sankaranarayanasamy also carried out the steam explosion of HSFs as per the method reported by Sonia and Dasan for end-use as a reinforcement in epoxy-matrix-based polymer composites. ${ }^{119}$

\section{Synthesis of cellulose nanofibres, nanowhiskers and nanocrystals}

\section{Synthesis of nanofibres}

Kian and co-workers ${ }^{120}$ isolated nanocrystalline cellulose from pre-synthesized microcrystalline HSFs using the acid hydrolysis technique. In the first step, they treated the micro-HSFs with $50 \mathrm{wt} \%$ sulphuric acid at $45{ }^{\circ} \mathrm{C}$ for different time intervals (30, 45 and $60 \mathrm{~min})$ under strong mechanical agitation and subsequently diluted the mixture with ice cubes to halt the hydrolysis process. The mixture was then centrifuged, subjected to dialysis for 7 days to increase its $\mathrm{pH}$ to 5 and finally ultrasonicated for $30 \mathrm{~min}$ at $20 \mathrm{kHz}$. The prepared nanocellulose samples were characterized using various techniques including transmission electron microscopy (TEM), SEM, atomic force microscopy (AFM), field emission SEM (FESEM), dynamic light scattering (DLS) and energy dispersive X-ray spectroscopy (EDS), which confirmed that the synthesized cellulose nanofibres had a width of 6.84-13.06 nm (Fig. 6).

\section{Synthesis of cellulose nanocrystals (CNCs) and metal- nanoparticle-doped CNCs}

For the preparation of nanocellulose, cellulose extracted from HS stems was subjected to acid hydrolysis using $30 \%$ sulphuric acid at $80{ }^{\circ} \mathrm{C}$ by Goswami et al. ${ }^{38}$ The synthesized nanocellulose 

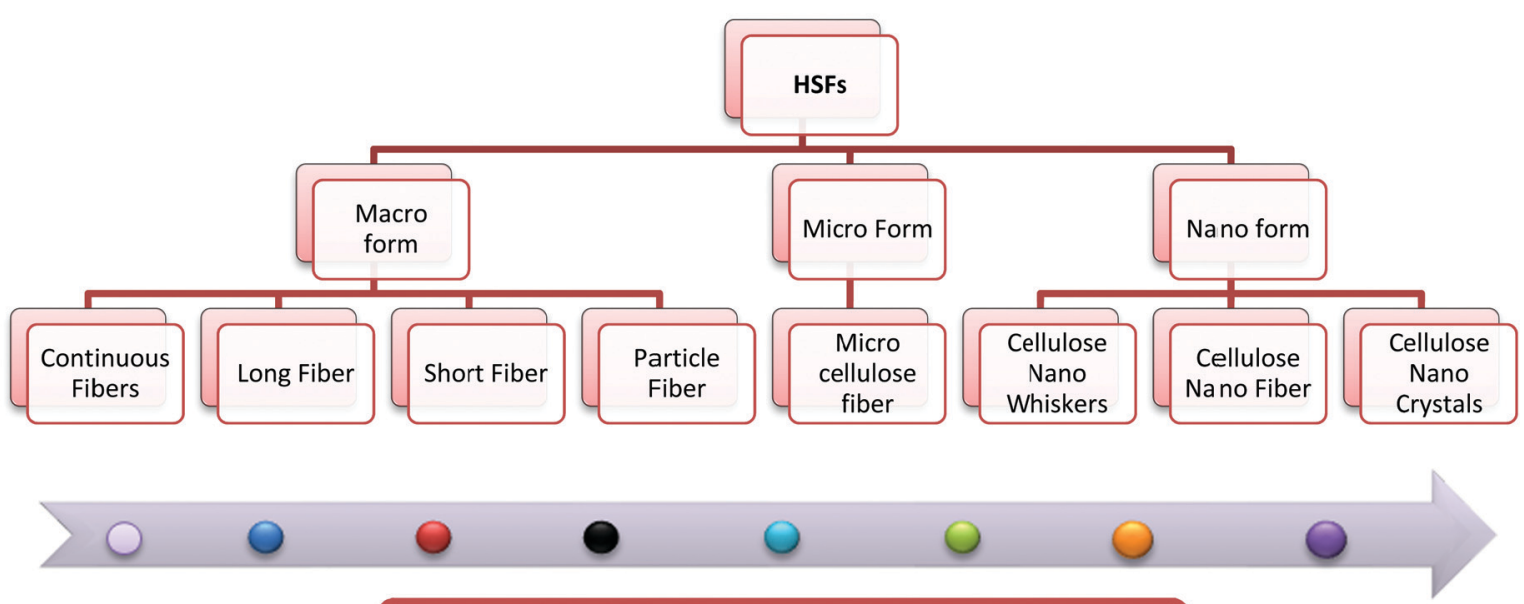

\section{Decreasing Fibre Dimensions}

Fig. 5 Different forms of HSFs that have been prepared/extracted from bast fibres.
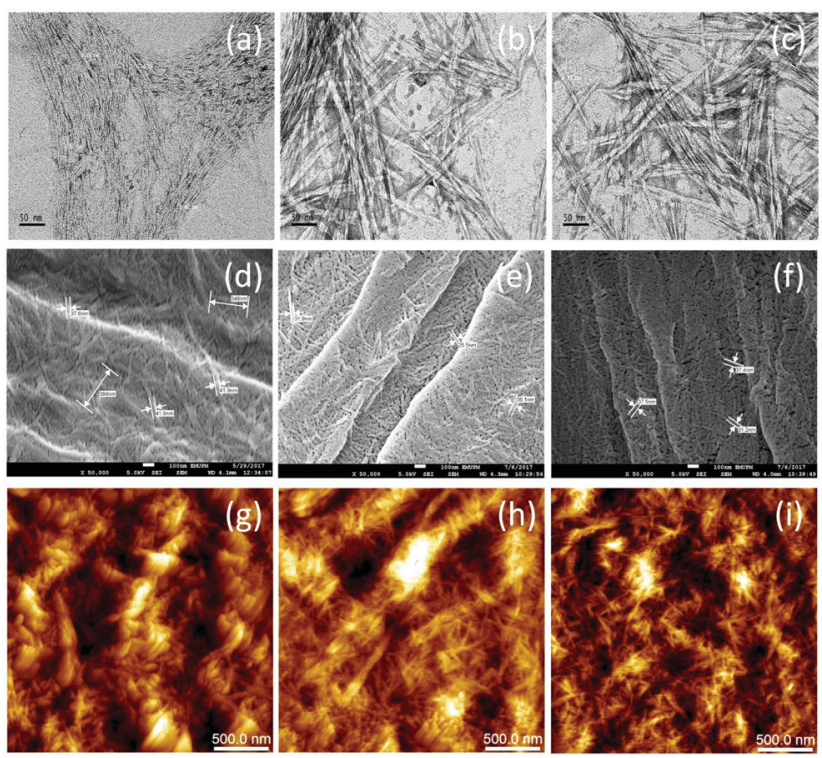

Fig. 6 TEM (a-c), FESEM (d-f), and AFM ( $g-i)$ images of NF-30 (a, $d$ and g), NF-45 (b, e and h), and NF-60 (c, f and i) (here, NF-30, 45, and 60 stand for samples hydrolysed for 30, 45, and $60 \mathrm{~min}$, respectively). Reprinted with permission from ref. 120. Copyright (2018) Elsevier.

was subsequently centrifuged for $10 \mathrm{~min}$ at $10000 \mathrm{rpm}$, washed with deionized water and finally freeze-dried to obtain cellulose nanocrystals (CNCs) (Fig. 7a). A yield of $44.8 \%$ was reported for this process. The acid hydrolysis technique is known to introduce some active $\mathrm{OH}$ groups onto cellulose because of the breakage of intramolecular and intermolecular hydrogen bonding in the cellulose, and thus some metal ions or functional groups can be anchored. Goswami et al. utilized this concept for the preparation of CNCs-supported Ag nanoparticles (Fig. 7b). For the synthesis, a mixture of $0.1 \mathrm{~g}$ of CNCs and $25 \mathrm{ml}$ of $2 \mathrm{mM}$ silver nitrate was initially ultrasonicated for 10 minutes, and then HS seeds in powdered form, which act as the reducing agent, were added to the mixture under vigorous stirring. The mixture was subsequently stirred continuously for half an hour until a change in the colour of the mixture from white to yellow was noted (Fig. 8). Various physical techniques including XRD, TEM, SEM and FETEM were used for the characterization of the silverparticle-doped CNCs, and it was reported that the bio-reducing agent led to the formation of silver nanoparticles with a diameter of $4 \pm 0.960 \mathrm{~nm}$ onto the surface of the CNCs (Fig. 7).

These silver-coated CNCs were further used for the degradation of various dyes such as eosin Y, bromophenol, methyl orange, methylene blue and orange $\mathrm{G}$, and it was reported that this bioadsorbent was highly effective in the removal of these dyes, with the dye solutions being discoloured within only $60 \mathrm{~min}$.

In a different study, Goswami et al. ${ }^{121}$ doped copper nanoparticles onto CNCs extracted from HSFs for end-use as a catalyst in aza-Michael reactions. They used $0.01 \mathrm{~g}$ of CNCs and $0.01 \mathrm{M}$ copper sulphate; instead of HS seeds, $0.01 \mathrm{M}$ ascorbic acid solution was used as a reducing agent in this case. Furthermore, they also used cetyltrimethylammonium bromide (CTAB) to control the size of the nanoparticles and sodium borohydride solution $(0.1 \mathrm{M})$ at the end to ensure the complete reduction of the copper ions. After FESEM, FETEM and XRD evaluation, copper nanoparticles with a size of $7 \mathrm{~nm}$ were found to have been doped onto the synthesized CNCs, which were reported to have a size of $49 \mathrm{~nm}$ (Fig. 9). The developed catalyst was reported to show chemoselective behaviour and was recovered and reused several times. Kian and Jawaid ${ }^{122}$ also synthesized nanocrystalline cellulose and cellulose nanowhiskers from HSFs as per the scheme shown in Fig. 10. They reported that the CNWs had higher thermal stability than nanocrystalline cellulose after analyzing the DSC and TGA curves.

\section{Cellulose nano whiskers (CNWs)}

Attempts were also made to synthesise cellulose nanowhiskers (CNWs) from HSFs by Kian et al. ${ }^{123}$ A low amplitude 


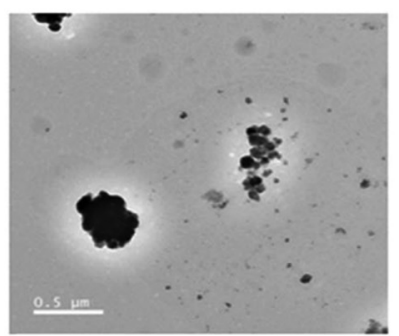

(a)

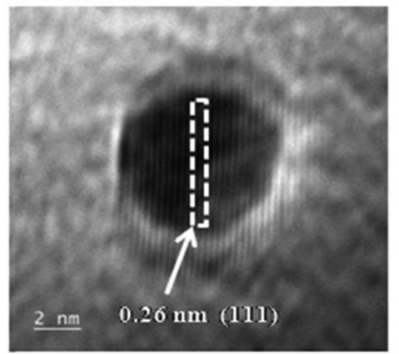

(e)

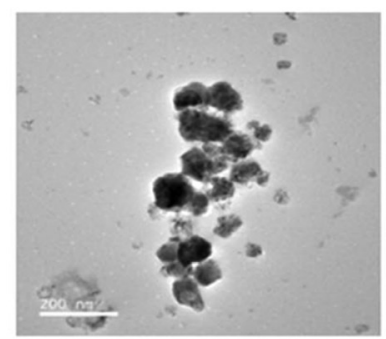

(b)

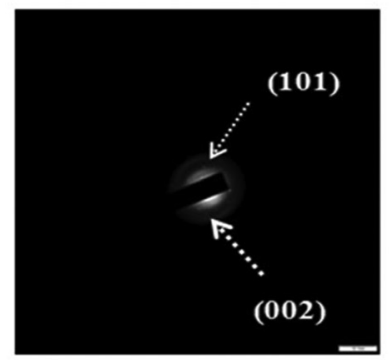

(I)

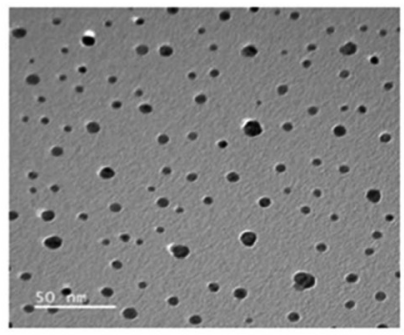

(c)

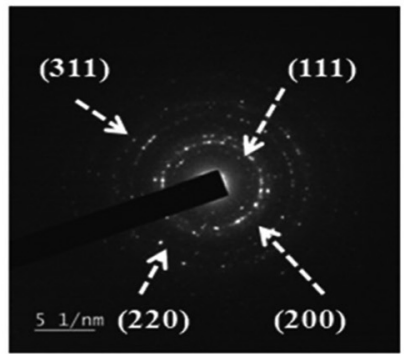

(g)

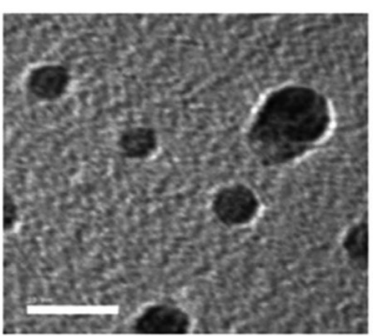

(d)

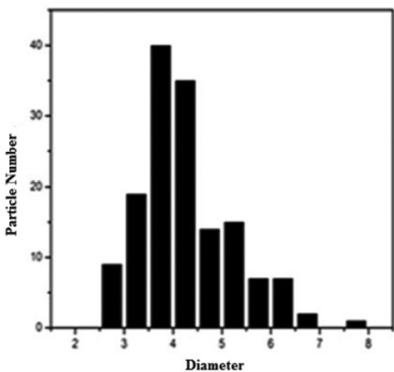

(h)

Fig. 7 TEM images of CNCs at (a) $500 \mathrm{~nm}$ and (b) $200 \mathrm{~nm}$ magnification. TEM images of CNCs doped with silver nanoparticles at (c) $50 \mathrm{~nm}$ and (d) $10 \mathrm{~nm}$ magnification. (e) A high-resolution image representing the clear fringe spacing, the SAED patterns of (f) CNCs, and (g) CNCs doped with silver nanoparticles, and (h) the average particle size distribution of the silver nanoparticles. ${ }^{38}$ Reprinted (adapted) with permission from Goswami et al. (2018). Copyright (2018) RSC.

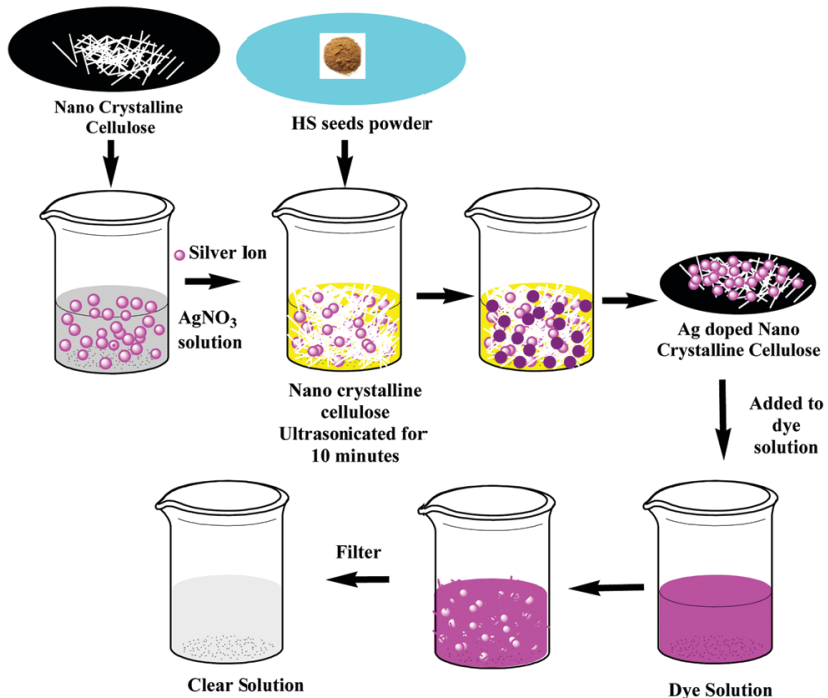

Fig. 8 A schematic diagram of the doping of silver nanoparticles onto nanocrystalline cellulose and the use of this material for dye removal. ${ }^{38}$

ultrasonication technique using amplitudes of 20,30 and $40 \%$ was employed for the fabrication of three different types of nanowhiskers with different dimensions, CNWs 1, CNWs 2 and CNWs 3. The synthesised samples were characterized using TEM, FESEM, AFM, DLS and XRD. An increase in the rod-like shape of the nanoparticles, percent crystallinity, formation of different sizes of nanowhiskers and the formation of a stable colloidal suspension (zeta potential $>-25 \mathrm{mV}$ ) was reported for CNWs2 and CNWs3.

\section{A comparison of the various forms of cellulosic fibres extracted from the HS plant}

The chemical composition, thermal stability, and crystallinity of the different forms of cellulosic fibres extracted from the HS plant are listed in Table 6. From the table, it can be concluded that moving from the macro- to the nano-dimensional forms of HSFs, the chemical composition, crystallinity, and thermal stability of the fibres increases. Furthermore, comparing cellulosic fibres extracted from the bast and the seeds of the HS plant, the former were reported to have better thermal and crystalline properties.

\section{Techniques utilized for the surface tailoring of HSFs and the physicochemical properties of the treated fibres}

The inherent drawbacks of PFs, such as high moisture absorption, water swelling, degradation, poor chemical and fire resistance, high dispersion of mechanical properties and poor adhesion with thermosetting/thermoplastic or cementitious matrices, have limited their role in composite industries. ${ }^{130-132}$ For this reason, efforts have been made by researchers to tailor the surface of PFs utilizing various techniques such as mercerization, silylation, benzoylation, cyano-ethylation, etherification, esterification and graft co-polymerization to meet the requirements for current challenging applications in the water 


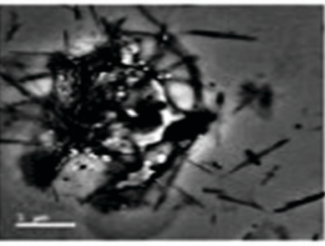

(a)

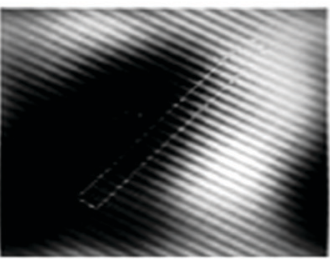

(e)

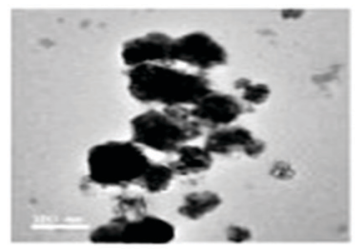

(b)

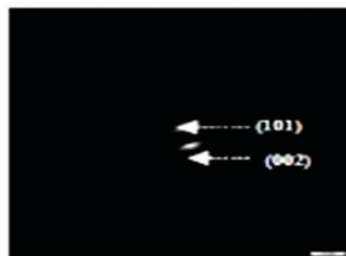

(1)

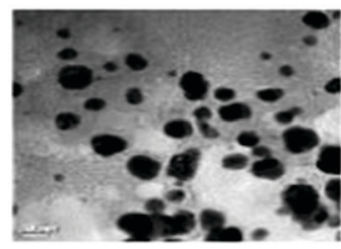

(c)

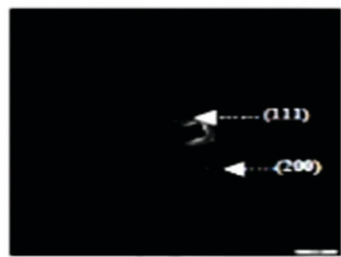

(a)

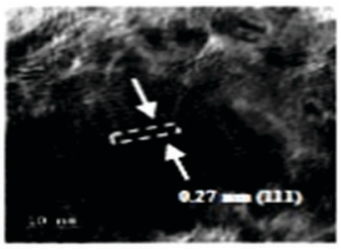

(d)

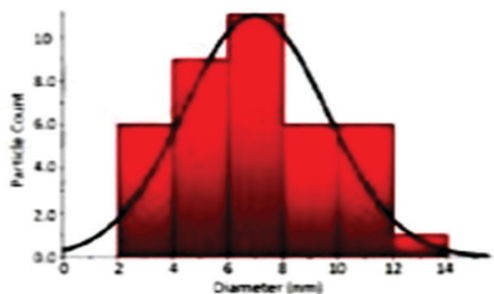

(h)

Fig. 9 TEM images of (a) pure cellulose, (b) CNCs, and (c) copper-particle-doped CNCs at a magnification of $10 \mathrm{~nm}$; (d and e) high-resolution images showing the lattice spacing in the CNC-doped-copper nanoparticles; ( $f$ ) and (g) SAED patterns of CNCs and CNCs doped with copper nanoparticles; and (h) the average particle size distribution of the copper nanoparticles. ${ }^{121}$ Reprinted (adapted) with permission from Goswami et al. (2018). Copyright (2018) Elsevier.

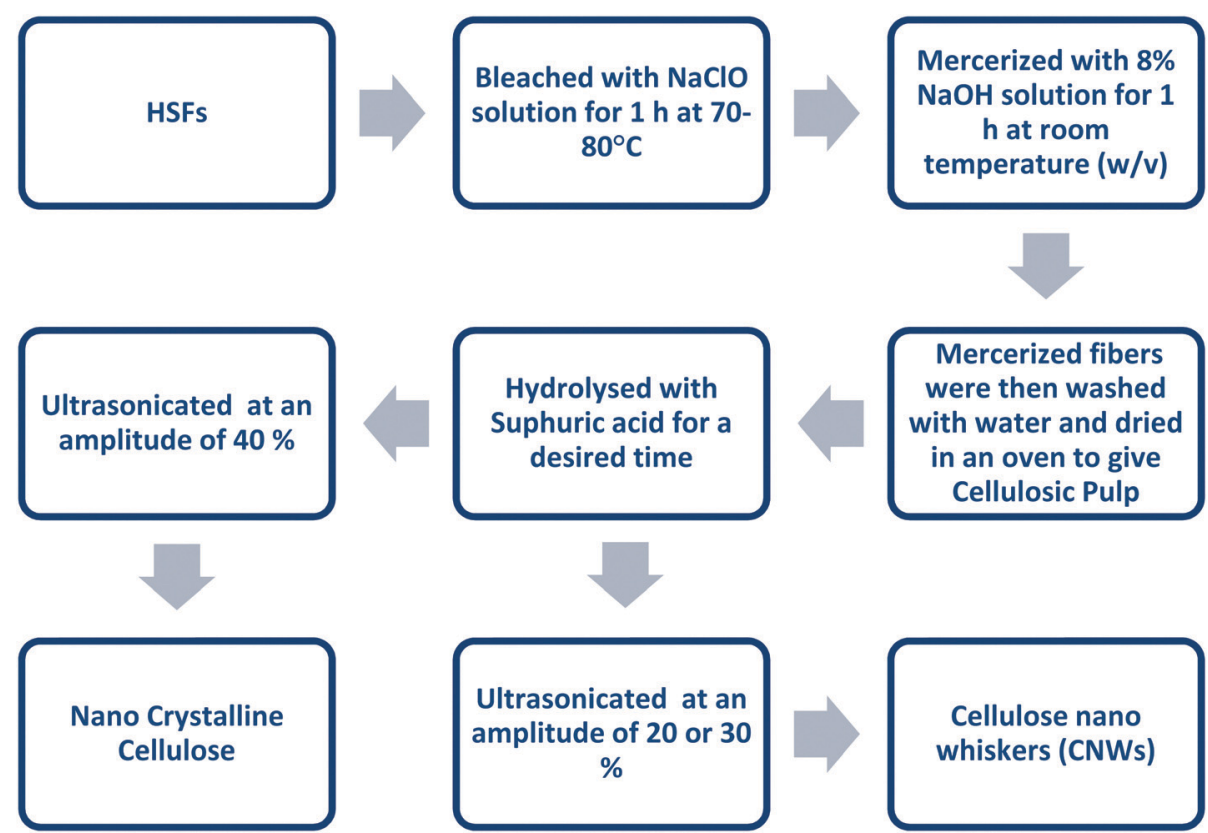

Fig. 10 A schematic diagram of the synthesis of nanocrystalline cellulose and CNWs from HSFs. ${ }^{42}$

treatment and polymer industries. ${ }^{115,133-135}$ Furthermore, researchers have also tried to control the surface characteristics of the different macro-HSFs; the results are summarized in Table 7 (Fig. 11). However, no data has been reported on the surface functionalization of the micro- and nanoforms of HSFs.

Nadlene et al. ${ }^{125}$ mercerized HSFs with 3, 6 and 9\% alkali solution and found improvement in the thermal stability, mechanical strength and physical characteristics of the fibres. Singha et $a{ }^{83}$ treated HSFs with $2 \% \mathrm{NaOH}$ solution for different time intervals ranging from 45-315 min to optimize the mercerization time in terms of fibre weight loss during the specified time. After optimizing the treatment time, they further optimized the alkali concentration by varying it from 2-14 wt\%. The results showed maximum weight loss when the HSFs were treated with $6 \%$ alkali solution for $180 \mathrm{~min}$. Furthermore, the mercerized fibres were then subjected to silylation by immersing them in an ethanol:water mixture $(60: 40 \mathrm{v} / \mathrm{v})$ with a $\mathrm{pH}$ of 4 for $90 \mathrm{~min}$. Improvements in the thermal quality, chemical resistance, percent swelling and water uptake behaviour of the HSFs were noticed after 
Table 6 A comparison of the chemical constituents, thermal quality, and crystallinity index of different forms of HSFs

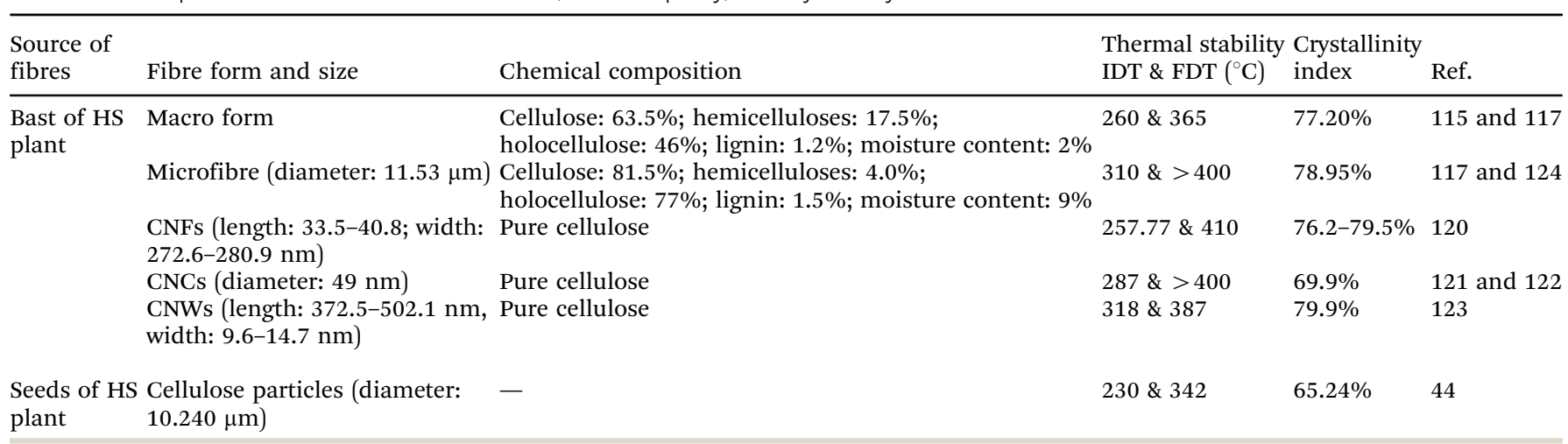

silylation. Chauhan and Kaith ${ }^{82,106,115,126-129,136}$ carried out graft copolymerization of numerous single and binary monomer mixtures onto HSFs using ceric ammonium nitrate (CAN)/nitric acid $\left(\mathrm{HNO}_{3}\right)$ as initiator system (Fig. 12). They optimized the reaction parameters including the time, temperature, and concentrations of monomer, nitric acid and CAN to obtain the maximum graft yield (Table 7 ). The various types of primary and binary monomer mixture graft copolymers are listed in Table 7. Comparing the thermal stability shows that HSFs-g-polymethylmethacrylate (MMA) has the maximum stability, followed by HSFs- $g$-poly[butylacrylate (BA) + ethylacrylate (EA)], HSFs- $g$ poly[acrylonitrile (AN) + BA], HSFs- $g$-poly(EA), HSFs- $g$-poly(EA + BA), HSFs- $g$-poly(BA), HSFs- $g$-poly[EA + 4-methylpyridine (VP)], HSFs- $g$-polymethyl acrylate (MA), HSFs- $g$-poly(AN+ MA), HSFs- $g$ poly[EA + acrylic acid(AA)], HSFs- $g$-poly(MA+ VA), HSFs- $g$-poly[BA + methylmethacrylate (MMA)], HSFs- $g$-poly(BA + MA), HSFs- $g$ poly(MA + AN), HSFs- $g$-poly(BA + AA), HSFs- $g$-poly(MA + AA), HSFs- $g$-poly[MA + acrylamide (AAm)], HSFs- $g$-poly(BA + AAm), HSFs- $g$-poly(AN + AAm), HSFs- $g$-poly(AN +2 VP) and HSFs- $g$ poly(AN) graft copolymers. Further, a slight decrease in the percent crystallinity was also noticed after graft copolymerization of monomer mixtures, which may be due to disruption in the crystalline lattice structure of the HSFs after surface tailoring. Adewuyl and co-workers ${ }^{44}$ studied the impact of the grafting of ethylenediamine onto chloroacetylated HSFs on their thermal quality. Sodium lauryl sulphate has been also applied to tailor the surface characteristics of HSFs by groups of researchers, ${ }^{33,81}$ and significant enhancements in tensile strength and water adsorption behaviour after surface tailoring were reported. Efforts were also made by Oladimeji and Onukwuli ${ }^{81}$ to tailor the surface of HSFs by employing ethylenediamine tetraacetic acid. They found an increase in the hydrophobic character and tensile strength of treated fibres because of the removal of waxes and hemicelluloses.

\section{HSF-Reinforced polymer composites}

The use of PFs to strengthen polymer matrices has attracted remarkable consideration in different applications in light of the useful properties and advantages of PFs over synthetic strands, such as their low density, biodegradability, biocompatibility, ease of processing, reduced harm to processing hardware, better tensile and flexural moduli, the improved surface finish of the produced composite parts, sustainable assets, plentiful accessibility, adaptability and insignificant danger to well-being. ${ }^{137-139} \mathrm{PF}$ composites with high specific stiffness and strength can be produced by adding tough and less-dense natural fibres into thermoplastic, thermoset, and bio-compatible or cementitious matrices. ${ }^{140}$ Researchers have utilized several polymer matrices for the development of HSF-fortified composite materials (Fig. 13). Additionally, the impact of the dimensions, i.e., of the macro-, micro- and nanoforms of HSFs on the properties of the resulting composites have been evaluated.

\section{Micro-HSF-reinforced epoxy composites}

Karakoti et al. fabricated micro-HSF-reinforced epoxy-matrixbased bio-composites by varying the loading of the fibres from 10 to 20,30 and $40 \%$ (by weight) and subsequently evaluated their mechanical (hardness, mechanical and impact strength) behaviour. ${ }^{141}$ The results showed an enhancement in the mechanical properties of polymer composites with an increase in percent fibre loading up to $30 \mathrm{wt} \%$. The maximum increases in hardness, impact, and tensile strength were reported to be 9.35\%, $48.20 \%$ and $17.74 \%$, respectively. Chandramohan and Bharanichandar ${ }^{142}$ utilized an alkali-treated powdered form of HSFs, either alone or in a hybrid mixture with powdered sisal and banana fibres, for the fabrication of epoxy-matrixreinforced polymer composites for automobile applications and reported an increase in the tensile and hardness properties of the resulting composites. In another study, Chandramohan et $a l .{ }^{143}$ tried to develop sisal, banana, HSFs and their hybrid mixtures into reinforced bio-epoxy matrix-based biomaterials for their application in orthopaedics. They reported that orthopaedics alloys, i.e., titanium, zirconia, stainless steel, and cobalt chrome, could be replaced with natural-fibrereinforced bio-epoxy bone plates for repairing fractured bones in human beings, either internally or externally. Similar to the work of Karakoti et al. Nallusamy also used different HSF loadings of 10, 20, 30 and $40 \mathrm{wt} \%$ for the reinforcement of epoxy matrix. The only difference was in the length of the fibres, as the former used microform HSFs whereas the latter preferred HSFs with a length of 2-4 mm. ${ }^{144} \mathrm{He}$ also reported maximum tensile strength (39 MPa), compressive (40 MPa) and 


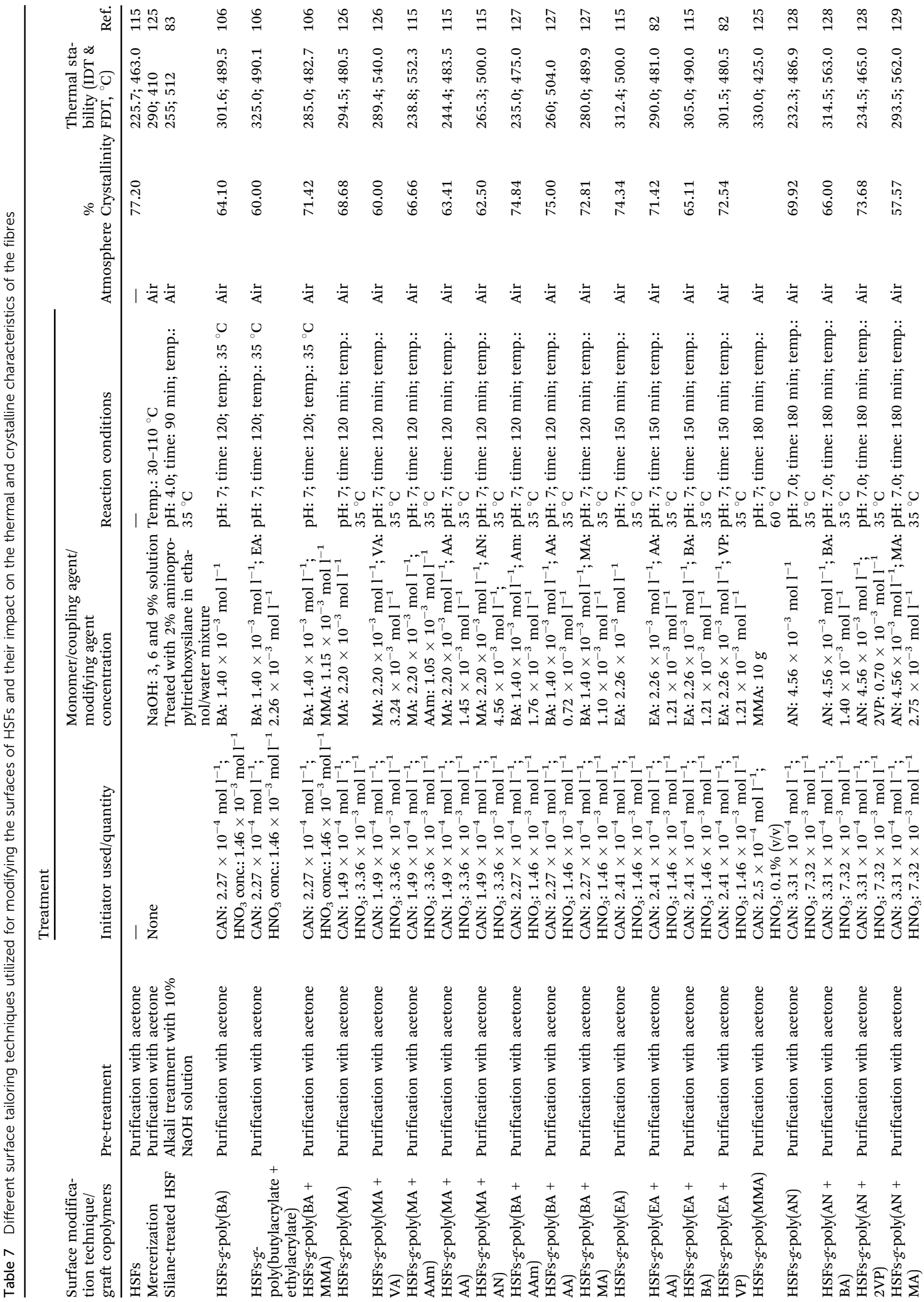


hardness (98 MPa) parameters for the 30\%-HSF-loaded polymer composites.

\section{Cardanol-matrix-based bio-composites}

A hybrid mixture of $10 \mathrm{wt} \%$ mercerized abaca with a varying amount $(0,5,10$ or $15 \mathrm{wt} \%)$ of mercerized HSFs (20 mm length) was used for the development of cardanol-matrix-based biocomposites. ${ }^{145}$ The optimum tensile strength of $58 \mathrm{MPa}$, yield strength of $44 \mathrm{MPa}$, micro-hardness of $51 \mathrm{HV}$ and density of $1.1 \mathrm{~g} \mathrm{~cm}^{-3}$ were found at a $10 \%$ abaca $+10 \%$ HSFs hybrid mixture loading. Furthermore, the fibre-loaded composites were reported to have better overall properties than the virgin matrix.

\section{Polypropylene-matrix-based composites}

Tasdemier et al. ${ }^{146}$ mercerized HSFs with a length shorter than $10 \mathrm{~mm}$ using a $20 \% \mathrm{NaOH}$ solution before their utilization as a reinforcement with loadings of 10,20 or $30 \%$ in polypropylene/ $10 \%$ maleic anhydride polypropylene (MAPP) matrix-based biocomposites. The injection-moulding technique was utilized for the production of the composites. Improvements in the tensile strength and elastic modulus were reported with increasing percent fibre loading. However, the impact and percent elongation parameters were reported to decrease with increasing loading. Another research group, that of Junkasem et al., ${ }^{147}$ studied the impact of varying the amount of HSFs (0-50\%) and MAPP (0-10\%) on the properties of the resulting isotactic polypropylene composites. They used four different types of HSFs having different dimensions, namely, bast fibre (average diameter: $0.230 \mathrm{~mm}$ ), core fibres (diameter: 0.450; length: 0.817-2.4007 mm), whole-stalk fibre mesh (0.817-2.4007 mm) and core-added whole-stalk-fibre mesh (0.817-2.4007 mm) for the fabrication of composites and reported that the pure HSF bast fibres showed the best overall performance in terms of mechanical properties (impact, flexural and tensile strength) at a $30 \%$ fibre loading. The inclusion of pure core fibres was found to improve only the flexural and Young's moduli. Furthermore, the maximum enhancement in mechanical properties was observed at a $40 \%$ and $7 \%$ loading of HSFs and MAPP, respectively.

\section{Urea formaldehyde (UF)-matrix-based HSF composites}

Singh and Thakur ${ }^{148}$ utilized dried HSFs with a size of $3 \mathrm{~mm}$ for the development of compression-moulded UF-based bio-composites with varying stacking of the fibres $(0-40 \%)$. The optimum mechanical properties, i.e., compressive modulus $\left(1197.0 \mathrm{~N} \mathrm{~mm}^{-2}\right)$, tensile modulus (233.54 $\mathrm{N} \mathrm{mm} \mathrm{mm}^{-2}$ ) and flexural modulus $\left(3578.90 \mathrm{~N} \mathrm{~mm}^{-2}\right)$ were reported at $30 \%$ fibre stacking. Furthermore, a slight decrease in the thermal properties of the fibre-reinforced UF composites was also reported. In another study, Singha and Thakur ${ }^{149}$ utilized HSFs with three different dimensions, i.e., particles (200 micron), short fibres (3 $\mathrm{mm})$ and long fibres $(6 \mathrm{~mm})$ for the fabrication and development of UF composites by adopting the same procedure as reported in the case of short-fibre-based polymer composites (Fig. 14). The results showed an increase in the mechanical properties with increasing fibre stacking up to $30 \%$. Maximum 


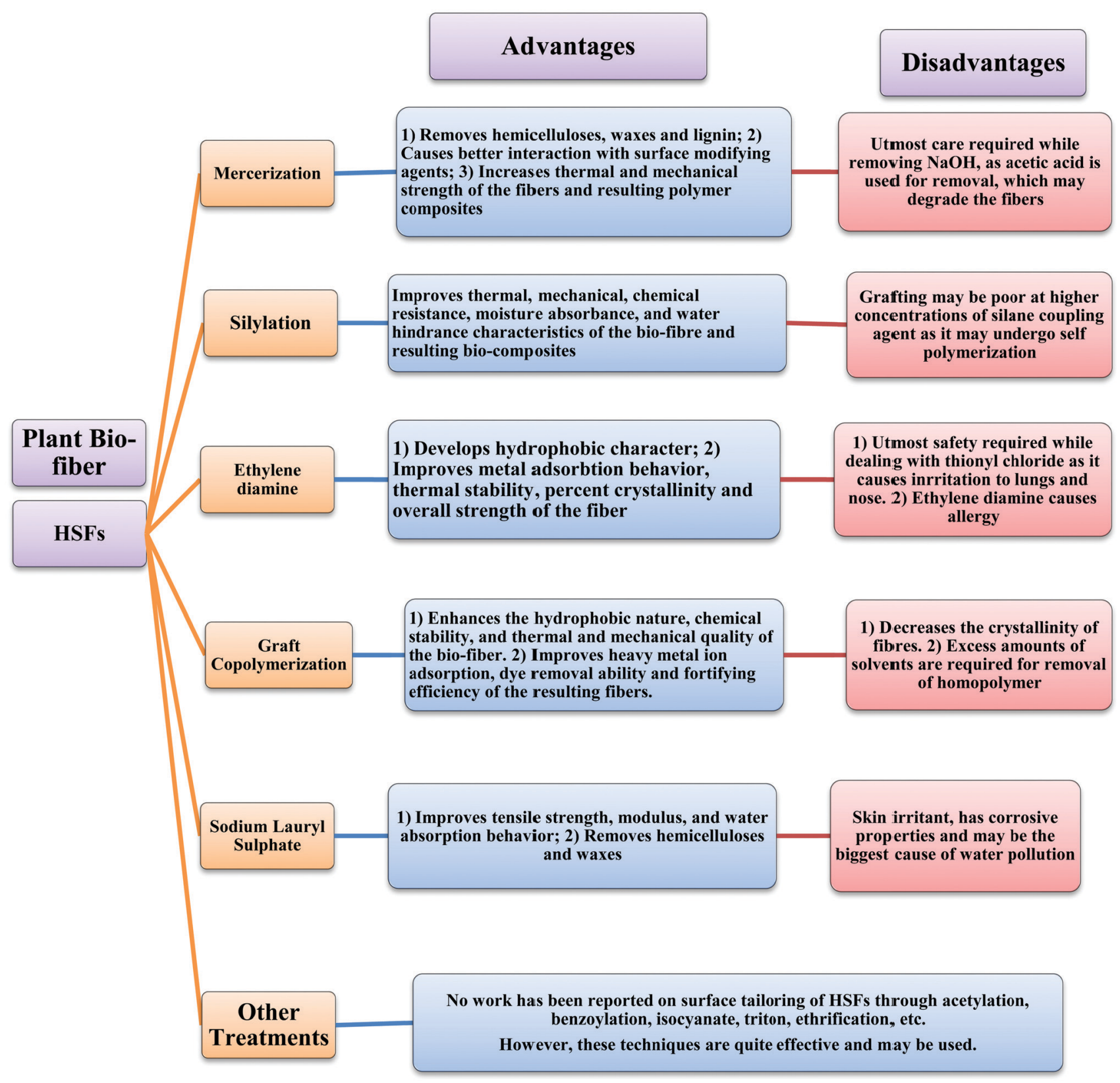

Fig. 11 Different chemical treatment methods utilized for the surface tailoring of HSFs.

tensile strengths of $332.8,307.6$ and $286.1 \mathrm{~N}$ and compressive strengths of $2586.5,2466.5$ and $2376.5 \mathrm{~N}$ were reported for the particle-, short- and long-fibre-fortified UF composites, respectively. From the above results, we can conclude that as the size of the fibres decreases, the interfacial adhesion between the matrix and the fibres increases. Additionally, the wear and thermal quality were also observed to be higher in the case of the particle- and fibre-fortified composites.

\section{Phenol formaldehyde (PF)-matrix-based Bio-composites}

Three different forms of HSFs, particle (200 microns), ${ }^{150}$ short $(3 \mathrm{~mm})^{151}$ and long $(6 \mathrm{~mm})^{152}$ HSFs, were used for the fortification of a self-assembling PF matrix by Singha and Thakur. The ratio of fibre (particle, short and long) stacking in the matrix was varied from 0 to $40 \%$ and the mechanical and thermal strength of the resulting composites were analyzed. Enhancement in the tensile, flexural, and compressive toughness was reported as a result of the fortification of the PF matrix with HSFs. Additionally, the optimum mechanical properties for the particle-, short- and long-fibrefortified composites were observed at $30 \%$ fibre stacking, and among the different forms, the particle-fibre-fortified PF composites had the upper hand in terms of mechanical strength, followed by the short- and long-fibre fortified ones. The tensile, compressive, and flexural strength for the particle-, short- and longfibre-fortified composites were reported to be 1325.0, 3535.3 and 1037.0 N; 1275.0, 3387.8 and 980.0 N; and 1247.0, 3302.4 and $940.0 \mathrm{~N}$, respectively. In addition, the thermal strength of the particle-fibre-fortified composites was also reported to be the 


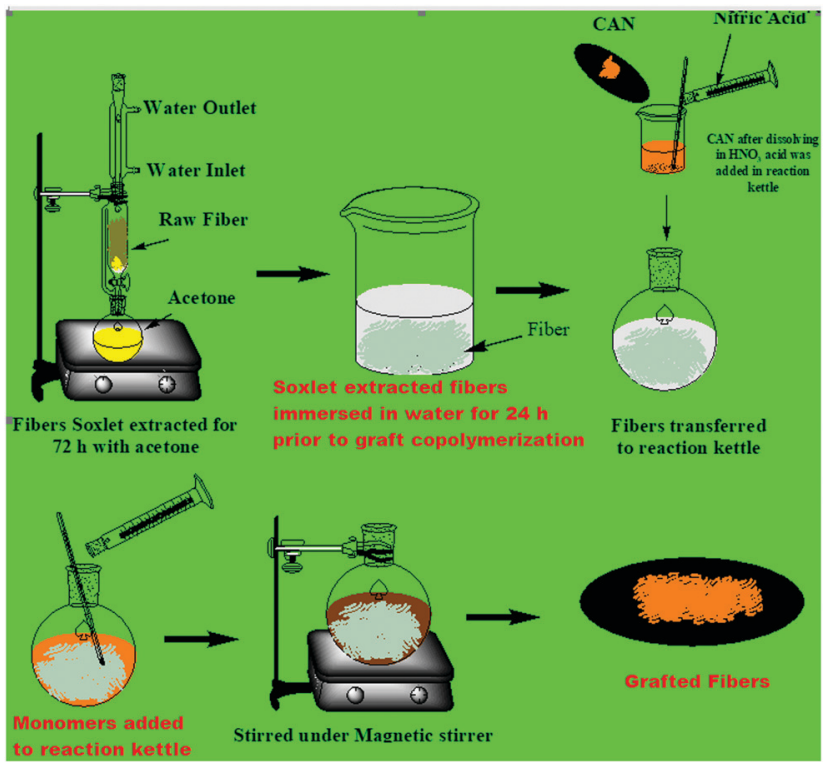

Fig. 12 Graft co-polymerization onto HSF fibres. ${ }^{47}$

highest, followed by those of the short- and long-fibre-fortified PF composites and the virgin matrix. Chauhan and Kaith ${ }^{153}$ also fabricated raw-HSF-reinforced PF-matrix-based composites and reported an increase in the mechanical properties of the virgin matrix after enhancement of the fibre loading. In other studies, Chauhan and Kaith ${ }^{106,154}$ used different surface-functionalized HSFs, including HSFs- $g$-poly(BA), HSFs- $g$-poly(BA + MMA), HSFs $-g$ poly(BA + EA), HSFs-g-poly(MA), HSFs- $g$-poly(MA + VA) and HSFs- $g$ poly(MA + EA) fibres, for the fortification of PF matrices, and reported enhanced hardness, flexural strength and Young's modulus after fortification of the PF matrix with $14 \%$ (wt.) of the surface-functionalized fibres. The maximum enhancement in the mechanical properties was reported for the HSFs-g-poly(BA + MMA)-fortified bio-polymers, followed by the HSFs-g-poly(BA)-, HSFs-g-poly(MA + EA)-, HSFs-g-poly(MA + VA)-, HSFs- $g$-poly(BA + EA)- and raw-HSF-fibre-reinforced $\mathrm{PF}$ composites. Pathania et al. studied the dielectric properties of HSFs- $g$-poly(AN) and HSFs- $g$ poly(EA) copolymer PF composites. ${ }^{155}$ They reported decreased dielectric constants and increased dissipation factors after fortification with the synthesized graft copolymers.

\section{Resorcinol-formaldehyde (RF)-matrix-based bio-composites}

To fabricate HSF-reinforced RF composites, Singha and Thakur, ${ }^{156,157}$ utilized three different forms of HSFs, particle, short and long fibres, in varying amounts of $0-40 \%$. They reported results similar to those obtained in the case of the HSF-fortified PF composites. The maximum mechanical strength was reported for particle-fibre-reinforced polymer composites (tensile strength: $690 \mathrm{~N}$; compressive strength:

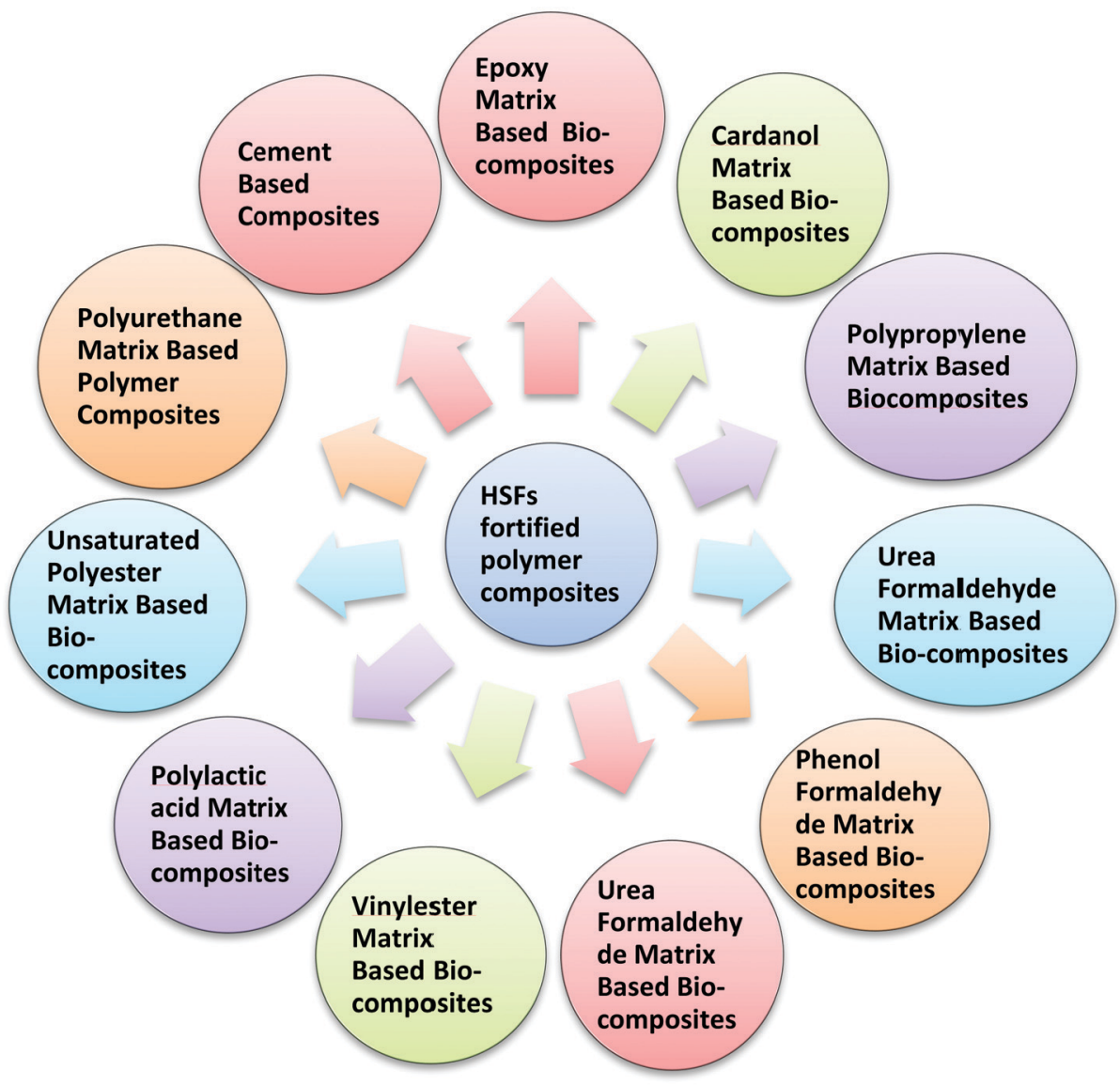

Fig. 13 Different types of HSF-fortified polymer composites reported in the literature. 

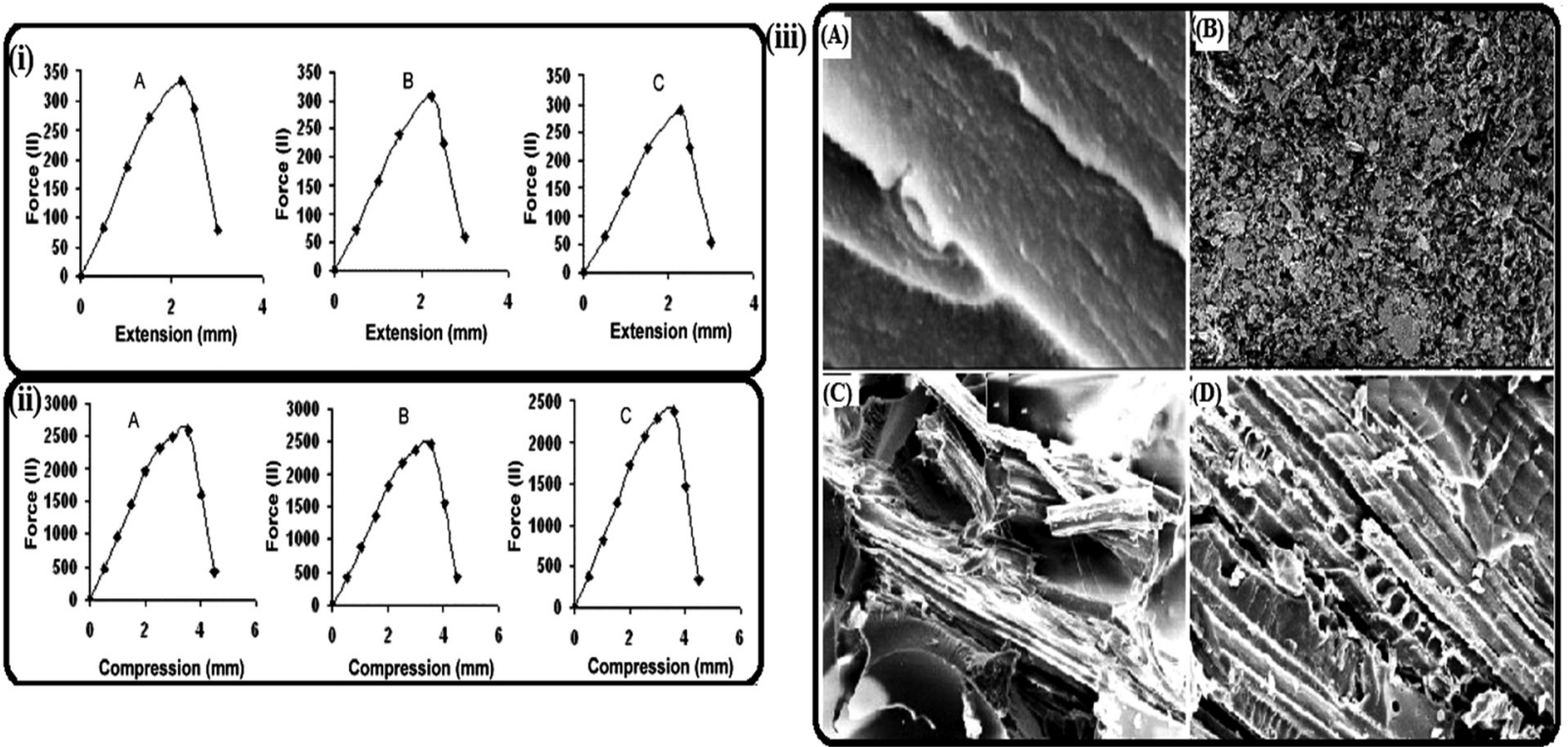

Fig. 14 Tensile (i) and compressive strength (ii) data for UF composites reinforced with (A) particle fibres, (B) short fibres, and (C) long fibres; (iii) SEM images of (A) virgin UF composites and UF composites reinforced with (B) particle fibres, (C) short fibres, and (D) long fibres. ${ }^{149}$ Reprinted (adapted) with permission from Singha and Thakur (2008). Copyright (2008) Springer

3193.50 N; Flexural Strength: $321.47 \mathrm{~N}$ ), followed by the short$(660.47 \mathrm{~N} ; 3053.50 \mathrm{~N} ; 310.0 \mathrm{~N})$ and long-fibre- $(637 \mathrm{~N} ; 2953 \mathrm{~N}$; flexural strength: $293 \mathrm{~N}$ ) fortified RF composites. Additionally, the particle-fibre composites were also reported to have the highest thermal stability.

\section{Vinyl ester (VE)-matrix-based bio-composites}

HSFs with a particle size of 100 to $425 \mu \mathrm{m}$ were used in different proportions $(5,10,15,20$ or $25 \mathrm{wt} \%)$ for the fabrication of VE-matrix-based bio-composites by Razali and co-workers. ${ }^{158}$ The maximum tensile modulus, strength and flexural strength were observed at $20 \%$ stacking of the fibres. An increase in the thermal properties of the resulting bio-composites with increasing percent fibre loading was also reported. In another study, Razali et $a l^{159}$ used a hybrid mixture of silane-treated sugar palm and HSFs with dimensions of 100 to $425 \mu \mathrm{m}$ for the development of polymer composites. They varied the relative proportions of oil palm and HSFs to fabricate vinyl-polymer-matrix-based biocomposites and reported higher tensile strength at a 50:50 relative loading of the hybrid mixtures. The flexural strength was observed to decrease after loading with the hybrid mixtures (Fig. 15). Navaneethakrishnan and Athijayamani ${ }^{160}$ used different percent loadings of long-form fibres $(6 \mathrm{~mm})$ for fabricating VE composites. The results showed a maximum tensile modulus and specific tensile modulus at 55.77 wt\% loading of the fibres; however, the tensile toughness was found to be greatest at 45.67 wt $\%$ stacking. Manickam and co-workers ${ }^{161}$ used the hand lay-up method to fabricate HSF-fortified VE composites. They immersed the composite specimens in three different water environments, namely ground water, distilled water and seawater, and compared the mechanical strength of the wet composite specimens with that of the dry specimens. The tensile strength was observed to be enhanced with increased fibre stacking in dry conditions; however, the opposite trend was found in wet conditions. Furthermore, the composite samples immersed in various water environments were reported to follow non-Fickian behaviour, and the maximum water adsorption behaviour was reported for the samples dipped in seawater. Nandele and co-workers $^{125}$ analyzed the effect of 3, 6 and 9\% alkali-treated
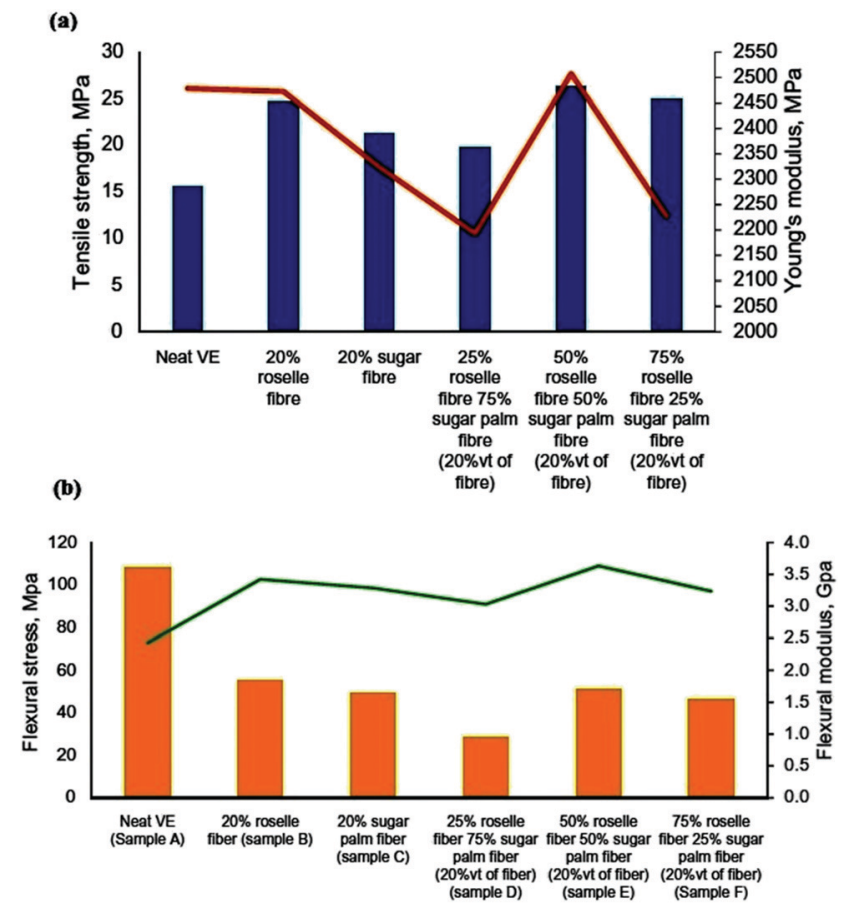

Fig. 15 Tensile (a) and flexural strength (b) data from various composite samples. ${ }^{159}$ Reprinted (adapted) with permission from Razali et al. (2018). Copyright (2018) Elsevier. 
and $6 \%$ alkali-treated + silane-coupled HSF loading ( $5 \mathrm{wt} \%$ ) on the mechanical toughness of the resulting vinyl ester composites. They observed enhanced interfacial adhesion of the fibres and the vinyl matrix after fibre surface tailoring. Additionally, among the silane-and alkali-treated fibres, the former were reported to be a better fortifying candidate.

\section{Polylactic acid (PLA)-matrix-based bio-composites}

Kian et al. ${ }^{162}$ utilized CNCs and cellulose nanowhiskers (CNWs) extracted from HSFs to fabricate PLA nanocomposites. They compared the fortifying ability of CNCs and CNWs to choose a suitable nanocomposite membrane for the removal of metal ions. Samples were characterized using various techniques, including a universal testing machine (UTM), AFM, TEM, and SEM. The results showed that the CNC-fortified PLA composites had better metal ion adsorption ability and thermal and mechanical quality than the CNW-fortified composites. However, the latter were reported to display better porous properties. Efforts were also made to enhance the metal ion adsorption potential of the CNC- and CNW-fortified membranes by selecting a dual-layer fabrication method and utilizing the vapour-prompt segregation method. In the dual-layer method, the nanocellulose content was varied from $1-3 \mathrm{wt} \%$, and the $3 \mathrm{wt} \%$-CNW-loaded composite membranes were reported to have better porosity. Additionally, better enhancement of the metal ion removal potential was also reported for the dual-layer fabricated membrane, with maximum values of 83 and $84 \%$ in the cases of $\mathrm{Co}^{2+}$ and $\mathrm{Ni}^{2+}$.

\section{Unsaturated polyester (UPE)-matrix-based bio-composites}

Hybrid mixtures (1:1 ratio) of HSFs and sisal fibres of different lengths (10, 50 and $150 \mathrm{~mm})$ with varying loadings $(10,20$ and $30 \%$ ) were utilized for fabricating UPE bio-composites by Athijayamani and co-workers. ${ }^{163}$ The impacts of dry and wet conditions on the performance of the composites were evaluated, and it was reported that with increasing fibre length and fibre loading, the tensile, flexural and impact toughness increased in dry conditions; however, the opposite trend was noted in the case of wet conditions. In a continuation of the previous study, Athijayamani et al. ${ }^{164}$ varied the amount of a hybrid mixture (5 cm length each) of HSFs and sisal fibres from 30-55 wt $\%$ and reported an enhancement in the flexural and tensile strength with increasing content up to $55 \mathrm{wt} \%$. However, a decrease in impact strength was noted after 40 wt $\%$ loading of fibres. Ramu and Sakthivel ${ }^{165}$ also evaluated the effects of moisture on the performance of HSF-fortified polyester composites. They varied the fibre contents from 10-30 wt\% and found an enhancement in the mechanical properties of the composite specimens under dry conditions. Furthermore, for the moisture-condition samples, a non-significant change in flexural strength was noted with increasing percent loading. The wear resistance was reported to be maximum at $30 \%$ loading for both the dry- and moisturecondition samples.

\section{Polyurethane (PU)-matrix-based polymer composites}

For the synthesis of PU-matrix-based nanocomposites, a oneshot process was designed by Soundhar et al., ${ }^{166}$ which includes the addition and blending of different weight percentages of HSFs (1-2 wt\%) and spherical/amorphous nanosilica particles $(0.50-1 \mathrm{wt} \%)$ in a polyol for 10 minutes and subsequent incorporation of isocyanate. The mechanical strength of the developed composites was evaluated, and the optimum weight percentages were reported to be $2.0 \%, 0.78 \%$ and $1.0 \%$ for HSFs, spherical silica and amorphous silica, respectively. Additionally, the fabricated nanocomposites were also found to have extraordinary thermal and mechanical qualities. Radzi et al. ${ }^{167}$ treated the HSFs with varying concentrations $(3,6$ and $9 \%$ ) of alkali before their utilization for the reinforcement of the PU matrix. The results showed an improvement in the mechanical properties (flexural and tensile strength), thermal strength, density and water absorption behaviour of the composite materials with increasing sodium hydroxide concentration.

\section{Cement-based composites}

Ismail et al. ${ }^{168}$ evaluated the impact of the addition of different contents $(0.25,0.5,0.75,1.0,1.5,2.0$ and $3.0 \mathrm{wt} \%)$ of short HSFs on the mechanical properties of the resulting cement-based composite materials. A 53\% improvement in tensile strength (from 42.9 to $59.7 \mathrm{MPa}$ ) and a decrease in compressive toughness (from 59.7 to $42.9 \mathrm{MPa}$ ) with increasing percent loading were reported. The poor compressive toughness was attributed to the increase in porosity and voids after HSF addition. In addition, the brittle behaviour of cement has also been reported to be controlled after fortification with HSFs.

\section{Conclusions and future perspectives}

PF-Fortified composite materials exhibit multiple valuable properties, such as light weight, modest cost, and reduced solidity in comparison to synthetic fibres. Thus, PF composite products may be utilized for commercial purposes in construction, buildings, and the automotive industry. The use of raw or surfacetailored HSFs as a strengthening material in polymeric composites has a constructive effect on the mechanical and thermal behaviours of the polymers. Although various surface-tailoring techniques have been utilized to upgrade the physical, mechanical, and thermal properties of the macroscale forms of HSFs, this area still requires much more consideration, as very little work has been done on the usage of surface-tailored HSFs as fortifying agents in polymer composites, the surface functionalization of micro/nanofibres, the extraction of microfibre/nanofibre/nanocellulose from HSFs, or the utility of functionalized micro/nanofibrils in the fortification of matrices. Furthermore, nanoparticle-doped HSFs are quite viable for the removal of heavy metals and dyes from wastewater, and their effectiveness might be further improved by controlling the sizes of doped nanoparticles using some medicinal plant extracts. The seeds of the HS plant have exceptional medicinal qualities and have been utilized for the extraction of nanocellulose and to control the sizes of nanoparticles. Thus, finally, we can conclude that due to their high mechanical, thermal, and water hindrance properties and crystalline content, these fibres are strong competitors to other commonly known plant fibres. This plant is grown worldwide for 
its medical uses, so the extraction of cellulose and its further utilization represents an appropriate usage of waste biomass that would otherwise go to waste.

\section{Author contributions}

Ashvinder K. Rana: conceptualization, writing, editing. Vijay Kumar Thakur: supervision, editing.

\section{Conflicts of interest}

There are no conflicts to declare.

\section{Acknowledgements}

The authors wish to thank their parent institutes for providing the necessary facilities to accomplish this work. V. K. T. is also thankful for research support provided by the Royal Academy of Engineering (IAPP-33-24/01/2017; IAPP18-19\295), and UKIERI (DST/INT/UK/P-164/2017).

\section{References}

1 B. Ates, S. Koytepe, A. Ulu, C. Gurses and V. K. Thakur, Chem. Rev., 2020, 120, 9304-9362.

2 V. K. Thakur, A. S. Singha and B. N. Misra, J. Appl. Polym. Sci., 2011, 122, 532-544.

3 A. Pappu, K. L. Pickering and V. K. Thakur, Ind. Crops Prod., 2019, 137, 260-269.

4 V. K. Thakur, A. S. Singha, I. Kaur, R. P. Nagarajarao and Y. Liping, Int. J. Polym. Anal. Charact., 2010, 15, 397-414.

5 A. S. Singha and V. K. Thakur, Polym.-Plast. Technol. Eng., 2009, 48, 201-208.

6 A. S. Singha and V. Kumar Thakur, Eur. J. Chem., 2008, 5, 782-791.

7 S. P. Dubey, V. K. Thakur, S. Krishnaswamy, H. A. Abhyankar, V. Marchante and J. L. Brighton, Vacuum, 2017, 146, 655-663.

8 V. K. Thakur, A. S. Singha and M. K. Thakur, Adv. Polym. Technol., 2013, 32, E427-E435.

9 A. S. Singha and V. K. Thakur, Eur. J. Chem., 2008, 5, 1055-1062.

10 A. S. Singha, A. Shama and V. K. Thakur, Int. J. Polym. Anal. Charact., 2008, 13, 447-462.

11 A. S. Singha and V. K. Thakur, Eur. J. Chem., 2009, 6, 71-76.

12 L. Mohammed, M. N. Ansari, G. Pua, M. Jawaid and M. S. Islam, Int. J. Polym. Sci., 2015, 2015, 243947, DOI: 10.1155/2015/243947.

13 D. Zielińska, T. Rydzkowski, V. K. Thakur and S. Borysiak, Ind. Crops Prod., 2021, 161, 113188.

14 S. I. Voicu and V. K. Thakur, Curr. Opin. Green Sustain. Chem., 2021, 30, 100480.

15 S. Iravani and R. S. Varma, Green Chem., 2019, 21, 4839-4867.
16 H. Seddiqi, E. Oliaei, H. Honarkar, J. Jin, L. C. Geonzon, R. G. Bacabac and J. Klein-Nulend, Cellulose, 2021, 28, 1893-1931.

17 M. S. Ahamed, P. Ravichandran and A. R. Krishnaraja, IOP Conference Series: Materials Science and Engineering, IOP Publishing, 2021, vol. 1055, p. 012038.

18 M. Asim, G. M. Uddin, H. Jamshaid, A. Raza, U. Hussain, A. N. Satti, N. Hayat and S. M. Arafat, J. Build. Eng., 2020, 31, 101411.

19 A. L. Leao, R. Rowell and N. Tavares, Science and technology of polymers and advanced materials, Springer, 1998, pp. 755-761.

20 P. Singh, M. Khan and H. Hailemariam, J. Nutr. Health Food Eng., 2017, 6, 00212.

21 A. S. Singha and V. K. Thakur, Iran. Polym. J., 2008, 17, 541-553.

22 A. S. Singha and V. K. Thakur, Iran. Polym. J., 2008, 17, 861-873.

23 E.-S. Kao, M.-Y. Yang, C.-H. Hung, C.-N. Huang and C.-J. Wang, Food Funct., 2016, 7, 171-182.

24 G. Moyano, S. G. Sáyago-Ayerdi, C. Largo, V. Caz, M. Santamaria and M. Tabernero, J. Funct. Foods, 2016, 21, 1-9.

25 I. Borrás-Linares, S. Fernández-Arroyo, D. Arráez-Roman, P. A. Palmeros-Suárez, R. Del Val-Díaz, I. AndradeGonzáles, A. Fernández-Gutiérrez, J. F. Gómez-Leyva and A. Segura-Carretero, Ind. Crops Prod., 2015, 69, 385-394.

26 P. C. Standley, Trees and Shrubs of Mexico: OxalidaceaeTurneraceae, US Government Printing Office, 1923, vol. 23.

27 K. V. Peter, Underutilized and Underexploited Horticultural Crops, Vol. 04, New India Publishing, 2008, vol. 4.

28 I. Alshami and A. E. Alharbi, Asian Pac. J. Trop. Biomed., 2014, 4, 104-108.

29 D. M. Rasheed, A. Porzel, A. Frolov, H. R. El Seedi, L. A. Wessjohann and M. A. Farag, Food Chem., 2018, 250, 236-244.

30 K. L. Higginbotham, K. P. Burris, S. Zivanovic, P. M. Davidson and C. N. Stewart Jr, Food Control, 2014, 40, 274-277.

31 M. T. Olaleye, J. Med. Plants Res., 2007, 1, 9-13.

32 I. Jabeur, E. Pereira, L. Barros, R. C. Calhelha, M. Soković, M. B. P. Oliveira and I. C. Ferreira, Food Res. Int., 2017, 100, 717-723.

33 T. O. Azeez and D. O. Onukwuli, J. Sci. Ind. Res., 2018, 77, 525-532.

34 N. T. Phong, T. Fujii, B. Chuong and K. Okubo, J. Mater. Sci. Res., 2012, 1, 144.

35 J. Agarwal and E. Dedhia, IJEAT, 2019, 9, 2425-2428.

36 E. U. Akubueze, C. S. Ezeanyanaso, O. S. Muniru, F. C. Nwaeche, M. I. Tumbi, C. C. Igwe and G. N. Elemo, J. Mater. Sci. Res. Rev., 2019, 1-7.

37 K. N. Okeke, S. C. Onwubu, G. C. Iwueke and I. O. Arukalam, Matéria (Rio de Janeiro).

38 M. Goswami, D. Baruah and A. M. Das, New J. Chem., 2018, 42, 10868-10878.

39 M. S. Nazir, B. A. Wahjoedi, A. W. Yussof and M. A. Abdullah, BioResources, 2013, 8, 2161-2172. 
40 A. K. Rana, E. Frollini and V. K. Thakur, Int. J. Biol. Macromol., 2021, 182, 1554-1581.

41 M. N. Cazaurang-Martinez, S. R. Peraza-Sánchez and C. A. Cruz-Ramos, Cellul. Chem. Technol., 1990, 24, 629-638.

42 H. Chattopadhyay and P. B. Sarkar, PhD Thesis, Dacca University, 1945.

43 R. C. Sun and X. F. Sun, Carbohydr. Polym., 2002, 49, 415-423.

44 A. Adewuyi and F. V. Pereira, Kemija u industriji.

45 W. P. F. Neto, H. A. Silvério, N. O. Dantas and D. Pasquini, Ind. Crops Prod., 2013, 42, 480-488.

46 N. Razali, M. S. Salit, M. Jawaid, M. R. Ishak and Y. Lazim, BioResources, 2015, 10, 1803-1824.

47 F. Le Digabel and L. Avérous, Carbohydr. Polym., 2006, 66, 537-545.

48 M. J. John and R. D. Anandjiwala, Polym. Compos., 2008, 29, 187-207.

49 I. M. De Rosa, C. Santulli and F. Sarasini, Mater. Des., 2010, 31, 2397-2405.

50 X. Li, L. G. Tabil and S. Panigrahi, J. Polym. Environ., 2007, 15, 25-33.

51 A. Shahzad, J. Compos. Mater., 2012, 46, 973-986.

52 A. A. Yussuf, I. Massoumi and A. Hassan, J. Polym. Environm., 2010, 18, 422-429.

53 O. Faruk, A. K. Bledzki, H.-P. Fink and M. Sain, Prog. Polym. Sci., 2012, 37, 1552-1596.

54 J. Gassan, A. Chate and A. K. Bledzki, J. Mater. Sci., 2001, 36, 3715-3720.

55 Z. Zhu, M. Hao and N. Zhang, J. Nat. Fibers, 2018, 17, 101-112.

56 K. M. M. Rao and K. M. Rao, J. Compos. Constr., 2007, 77, 288-295.

57 K. Joseph, R. D. Tolêdo Filho, B. James, S. Thomas and L. H. de Carvalho, Revista Brasileira de Engenharia Agrícola e Ambiental, 1999, 3, 367-379.

58 M. Jawaid and H. A. Khalil, Carbohydr. Polym., 2011, 86, 1-18.

59 P. Davies, C. Morvan, O. Sire and C. Baley, J. Mater. Sci., 2007, 42, 4850-4857.

60 M. Sarikanat, Y. Seki, K. Sever and C. Durmușkahya, Composites, Part B, 2014, 57, 180-186.

61 S. S. Saravanakumar, A. Kumaravel, T. Nagarajan, P. Sudhakar and R. Baskaran, Carbohydr. Polym., 2013, 92, 1928-1933.

62 V. P. Arthanarieswaran, A. Kumaravel and S. S. Saravanakumar, Int. J. Polym. Anal. Charact., 2015, 20, 367-376.

63 Y. Seki, M. Sarikanat, K. Sever and C. Durmuşkahya, Composites, Part B, 2013, 44, 517-523.

64 C. U. Maheswari, B. R. Guduri and A. V. Rajulu, J. Appl. Polym. Sci., 2008, 110, 1986-1989.

65 S. Y. Nayak, S. S. Heckadka, P. P. Sarvade, R. Shenoy, R. Samant and P. Kaiser, Mater. Res. Express, 2019, 6, 125107.

66 K. Mayandi, N. Rajini, P. Pitchipoo, J. W. Jappes and A. V. Rajulu, Int. J. Polym. Anal. Charact., 2016, 21, 175-183.
67 K. Santhanam, A. Kumaravel, S. S. Saravanakumar and V. P. Arthanarieswaran, Int. J. Polym. Anal. Charact., 2016, 21, 267-274.

68 T. P. Sathishkumar, P. Navaneethakrishnan, S. Shankar and R. Rajasekar, Compos. Interfaces, 2013, 20, 575-593.

69 V. S. Sreenivasan, S. Somasundaram, D. Ravindran, V. Manikandan and R. Narayanasamy, Mater. Des., 2011, 32, 453-461.

70 R. Vijay, A. Vinod, D. L. Singaravelu, M. R. Sanjay and S. Siengchin, Int. J. Lightweight Mater. Manuf., 2021, 4, 43-49.

71 S. S. Munawar, K. Umemura and S. Kawai, J. Wood Sci., 2007, 53, 108-113.

72 I. M. De Rosa, J. M. Kenny, M. Maniruzzaman, M. Moniruzzaman, M. Monti, D. Puglia, C. Santulli and F. Sarasini, Compos. Sci. Technol., 2011, 71, 246-254.

73 P. B. Sarkar, A. K. Mazumdar and K. B. Pal, J. Text. Inst., Trans., 1948, 39, T44-T58.

74 G. Venkata Reddy, S. Venkata Naidu and T. Shobha Rani, J. Reinf. Plast. Compos., 2009, 28, 2035-2044.

75 Z. Belouadah, A. Ati and M. Rokbi, Carbohydr. Polym., 2015, 134, 429-437.

76 O. Fadele, I. N. Oguocha, A. Odeshi, M. Soleimani and C. Karunakaran, J. Wood Sci., 2018, 64, 650-663.

77 J. R. M. d'Almeida, R. Aquino and S. N. Monteiro, Composites, Part A, 2006, 37, 1473-1479.

78 C. Uma Maheswari, K. Obi Reddy, A. Varada Rajulu and B. R. Guduri, J. Reinf. Plast. Compos., 2008, 27, 1827-1832.

79 M. J. M. Ridzuan, M. A. Majid, M. Afendi, S. A. Kanafiah, J. M. Zahri and A. G. Gibson, Mater. Des., 2016, 89, 839-847.

80 L. Mathew, K. U. Joseph and R. Joseph, J. Nat. Fibers, 2007, 3, 13-27.

81 A. T. Oladimeji and O. D. Okechukwu.

82 A. Chauhan and B. Kaith, J. Appl. Polym. Sci., 2012, 123, 1650-1657.

83 A. S. Singha, V. K. Thakur, I. K. Mehta, A. Shama, A. J. Khanna, R. K. Rana and A. K. Rana, Int. J. Polym. Anal. Charact., 2009, 14, 695-711.

84 Z. Wan, Z. Xiong, H. Ren, Y. Huang, H. Liu, H. Xiong, Y. Wu and J. Han, Carbohydr. Polym., 2011, 83, 264-269.

85 S. K. Saw, G. Sarkhel and A. Choudhury, Appl. Surf. Sci., 2011, 257, 3763-3769.

86 B. S. Kaith and S. Kalia, eXPRESS Polym. Lett., 2008, 2, 93-100.

87 N. Salamun, S. Triwahyono, A. A. Jalil, Z. A. Majid, Z. Ghazali, N. A. F. Othman and D. Prasetyoko, RSC Adv., 2016, 6, 34411-34421.

88 A. S. Singha and A. K. Rana, J. Appl. Polym. Sci., 2012, 124, 2473-2484.

89 T.-J. Chung, J.-W. Park, H.-J. Lee, H.-J. Kwon, H.-J. Kim, Y.-K. Lee and W. Tai Yin Tze, Appl. Sci., 2018, 8, 376.

90 S. Oza, H. Ning, I. Ferguson and N. Lu, Composites, Part B, 2014, 67, 227-232.

91 A. S. Singha, A. Guleria, R. K. Rana and A. K. Rana, Int. J. Polym. Anal. Charact., 2013, 18, 377-389. 
92 M. J. P. Macedo, G. S. Silva, M. C. Feitor, T. H. C. Costa, E. N. Ito and J. D. D. Melo, J. Mater. Res. Technol., 2020, 9, 2467-2476.

93 A. S. Singha and R. K. Rana, J. Appl. Polym. Sci., 2012, 124, 1891-1898.

94 S. Kalia and R. Sheoran, Int. J. Polym. Anal. Charact., 2011, 16, 307-318.

95 A. K. Mohanty, P. C. Tripathy, M. Misra, S. Parija and S. Sahoo, J. Appl. Polym. Sci., 2000, 77, 3035-3043.

96 S. Kalia and S. Vashistha, J. Polym. Environ., 2012, 20, 142-151.

97 M. Kathirselvam, A. Kumaravel, V. P. Arthanarieswaran and S. S. Saravanakumar, Int. J. Biol. Macromol., 2019, 129, 396-406.

98 S. Indran, R. E. Raj and V. S. Sreenivasan, Carbohydr. Polym., 2014, 110, 423-429.

99 K. O. Reddy, B. Ashok, K. R. N. Reddy, Y. E. Feng, J. Zhang and A. V. Rajulu, Int. J. Polym. Anal. Charact., 2014, 19, 48-61.

100 M. Sfiligoj, S. Hribernik, K. Stana and T. Kree, in Advances in Agrophysical Research, ed. S. Grundas, InTech, 2013.

101 A. C. H. Barreto, M. M. Costa, A. S. B. Sombra, D. S. Rosa, R. F. Nascimento, S. E. Mazzetto and P. B. A. Fechine, J. Polym. Environ., 2010, 18, 523-531.

102 K. L. Pickering, G. W. Beckermann, S. N. Alam and N. J. Foreman, Composites, Part A, 2007, 38, 461-468.

103 P. Senthamaraikannan, S. S. Saravanakumar, V. P. Arthanarieswaran and P. Sugumaran, Int. J. Polym. Anal. Charact., 2016, 21, 207-213.

104 A. S. Singha and R. K. Rana, Int. J. Polym. Anal. Charact., 2010, 15, 27-42.

105 M. Jonoobi, K. O. Niska, J. Harun and M. Misra, BioResources, 2009, 4, 626-639.

106 A. Chauhan and B. Kaith, Waste Biomass Valorization, 2012, 3, 141-148.

107 A. S. Singha and A. K. Rana, J. Polym. Environ., 2012, 20, 361-371.

108 E. Fortunati, D. Puglia, M. Monti, C. Santulli, M. Maniruzzaman, M. L. Foresti, A. Vazquez and J. M. Kenny, J. Polym. Environ., 2013, 21, 726-737.

109 B. Bakri, Naharuddin, A. E. E. Putra, I. Renreng, H. Arsyad and A. A. Mochtar, IOP Conf. Ser.: Earth Environ. Sci., 2018, 175, 012001.

110 V. K. Kaushik, A. Kumar and S. Kalia, TEXTILE, 2013, 1, 101-105.

111 Y. Cao, F. Chan, Y.-H. Chui and H. Xiao, BioResources, 2012, 7, 4109-4121.

112 Y. Sun, L. Lin, H. Deng, J. Li, B. He, R. Sun and P. Ouyang, BioResources, 2008, 3, 297-315.

113 Q. Chen, T. Zhao, M. Wang and J. Wang, Color. Technol., 2013, 129, 448-453.

114 N. R. J. Hyness, N. J. Vignesh, P. Senthamaraikannan, S. S. Saravanakumar and M. R. Sanjay, J. Nat. Fibers, 2018, 15, 146-153.

115 B. S. Kaith, A. Chauhan, A. S. Singha and D. Pathania, Int. J. Polym. Anal. Charact., 2009, 14, 246-258.
116 A. Karakoti, S. Biswas, J. R. Aseer, N. Sindhu and M. R. Sanjay, J. Nat. Fib., 2020, 17, 189-198.

117 A. Sonia and K. Priya Dasan, Carbohydr. Polym., 2013, 92, 668-674.

118 A. K. Sonia and K. P. Dasan, Sci. Eng. Compos. Mater., 2016, 23, 489-494.

119 J. R. Aseer and K. Sankaranarayanasamy, IOP Conf. Ser.: Mater. Sci. Eng., 2017, 272, 012020.

120 L. K. Kian, M. Jawaid, H. Ariffin and Z. Karim, Int. J. Biol. Macromol., 2018, 114, 54-63.

121 M. Goswami and A. M. Das, Carbohydr. Polym., 2018, 195, 189-198.

122 L. K. Kian and M. Jawaid, IJITEE, 2019, 9, 5430-5434.

123 L. K. Kian, M. Jawaid, H. Ariffin, Z. Karim and M. T. H. Sultan, Cellulose, 2019, 26, 6599-6613.

124 L. K. Kian, M. Jawaid, H. Ariffin and O. Y. Alothman, Int. J. Biol. Macromol., 2017, 103, 931-940.

125 R. Nadlene, S. M. Sapuan, M. Jawaid, M. R. Ishak and L. Yusriah, Polym. Compos., 2018, 39, 274-287.

126 A. Chauhan and B. Kaith, Chem. Sin., 2011, 2, 20-29.

127 A. Chauhan and B. Kaith, Am. J. Biochem. Mol. Biol., 2012, 3, 61-70.

128 A. Chauhan and B. Kaith, Polym. Renewable Resour., 2011, 2, 63-78.

129 A. Chauhan and B. Kaith, Fibers Polym., 2011, 12, 1-7.

130 A. K. Rana and A. S. Singha, Adv. Polym. Technol., 2014, 33(4), DOI: 10.1002/adv.21433.

131 A. S. Singha and A. K. Rana, Polym. Compos., 2012, 33, 1403-1414.

132 A. K. Rana and A. S. Singha, Polym. Sci., Ser. A, 2015, 57, 221-232.

133 Y. Habibi, Chem. Soc. Rev., 2014, 43, 1519-1542.

134 V. K. Thakur, M. K. Thakur and R. K. Gupta, Int. J. Polym. Anal. Charact., 2014, 19, 256-271.

135 V. K. Thakur, M. K. Thakur and R. K. Gupta, Carbohydr. Polym., 2014, 104, 87-93.

136 C. N. Saikia and F. Ali, Bioresour. Technol., 1999, 68, 165-171.

137 H. Ku, H. Wang, N. Pattarachaiyakoop and M. Trada, Composites, Part B, 2011, 42, 856-873.

138 D. Verma and K. L. Goh, Biomass, Biopolymer-Based Materials, and Bioenergy, Elsevier, 2019, pp. 51-73.

139 P. Peças, H. Carvalho, H. Salman and M. Leite, J. Compos. Sci., 2018, 2, 66.

140 Y. Xie, C. A. S. Hill, Z. Xiao, H. Militz and C. Mai, Composites, Part A, 2010, 41, 806-819.

141 A. Karakoti, A. Soundhar, M. Rajesh, K. Jayakrishna and M. T. B. H. Sultan, ijrte, 2019, 8, 477-480.

142 D. Chandramohan and J. Bharanichandar, Am. J. Environ. Sci., 2013, 9, 494-504.

143 D. Chandramohan, J. Bharanichandar, P. Karthikeyan, R. Vijayan and B. Murali, Am. J. Appl. Sci., 2014, 11, 623-630.

144 S. Nallusamy, $A E F, 2016,16,1-6$.

145 B. Vinod and M. Anandajothi, Mater. Res. Express, 2020, 6, 125363. 
146 M. Taşdemir, Ç. Gül and E. D. Kocak, in Sustainability in the Textile and Apparel Industries, ed. S. S. Muthu and M. A. Gardetti, Springer International Publishing, Cham, 2020, pp. 97-115.

147 J. Junkasem, J. Menges and P. Supaphol, J. Appl. Polym. Sci., 2006, 101, 3291-3300.

148 A. S. Singha and V. K. Thakur, Polym.-Plast. Technol. Eng., 2009, 48, 482-487.

149 A. S. Singha and V. K. Thakur, Bull. Mater. Sci., 2008, 31, 791-799.

150 A. S. Singha and V. K. Thakur, Polym. Polym. Compos., 2009, 17, 189-194.

151 A. S. Singha and V. K. Thakur, BioResources, 2008, 3, 1173-1186.

152 A. S. Singha and V. K. Thakur, Polym.-Plast. Technol. Eng., 2009, 48, 736-744.

153 A. Chauhan and B. Kaith, Polym. Renewable Resour., 2013, 4, 35-48.

154 A. Chauhan and B. Kaith, ISRN Mater. Sci., 2011, 2011, 1-7. 155 D. Pathania, D. Singh and D. Sharma, Optoelectron. Adv. Mater., Rapid Commun., 2010, 4, 1048-1051.

156 A. S. Singha and V. K. Thakur, Int. J. Polym. Mater., 2009, 58, 217-228.
157 A. S. Singha and V. K. Thakur.

158 N. Razali, S. M. Sapuan, M. Jawaid, M. R. Ishak and Y. Lazim, BioResources, 2016, 11, 9325-9339.

159 N. Razali, S. M. Sapuan and N. Razali, Natural Fibre Reinforced Vinyl Ester and Vinyl Polymer Composites, Elsevier, 2018, pp. 169-180.

160 S. Navaneethakrishnan and A. Athijayamani, J. Polym. Eng., 2015, 35, 665-674.

161 C. Manickam, J. Kumar, A. Athijayamani and J. Easter Samuel, Polym. Compos., 2015, 36, 1638-1646.

162 K. K. Lau, doctoral, Universiti Putra Malaysia, 2019.

163 A. Athijayamani, M. Thiruchitrambalam, U. Natarajan and B. Pazhanivel, Mater. Sci. Eng., A, 2009, 517, 344-353.

164 A. Athijayamani, M. Thiruchitrambalam, J. T. W. Jappes and A. Alavudeen, IJCAET, 2011, 3, 538.

165 G. V. S. P. Ramu, Int. J. Adv. Res., 2013, 1, 28-32.

166 A. Soundhar, M. Rajesh, K. Jayakrishna, M. T. H. Sultan and A. U. M. Shah, Nanocomposites, 2019, 5, 1-12.

167 A. M. Radzi, S. M. Sapuan, M. Jawaid and M. R. Mansor, Fibers Polym., 2019, 20, 847-855.

168 D. M. A. Ismail, AREJ, 2007, 15, 42-51. 